\title{
Extreme drought in the recent two decades in northern China resulting from Eurasian warming
}

\author{
Jie Zhang ${ }^{1} \odot$. Haishan Chen ${ }^{1} \cdot$ Qiang Zhang ${ }^{2}$
}

Received: 10 December 2017 / Accepted: 10 June 2018 / Published online: 21 June 2018

(c) The Author(s) 2018

\begin{abstract}
The analysis of 55-year daily precipitation data reveals prolonging in consecutive dry-day (CDD) and extreme summertime droughts in northern China since the 1990s. Anomalous CDD corresponds to a persistent anticyclone anomaly, that has a significant correlation with enhancing in Eurasian forced waves including Eurasian teleconnection (EU) pattern and Silk Road pattern (SRP), which have response to the upward wave activity flux over the key region $\left(40^{\circ} \mathrm{N}-70^{\circ} \mathrm{N}, 0^{\circ} \mathrm{E}-60^{\circ} \mathrm{E}\right)$ and other regions along the EU and SRP over Eurasia. Those are the partly significant forcing sources converting energy for the forced wave. It is hypothesized that increasing Eurasian heating is more notable with global warming, and it leads to increasing atmospheric baroclinicity in the lower troposphere, further for increasing wave activity flux, that is responsible for the enhancing EU and SRP, and finally contributes to enhancing anticyclone anomaly over northern China. These anomalous circulations may result in prolonging CDD and persistent summertime drought under anthropogenic warming as projected by global climate models.
\end{abstract}

Keywords Decadal drought $\cdot$ Forced wave $\cdot$ Eurasian warming

\section{Introduction}

Historical records have shown that northern China has suffered through numerous droughts. The consecutive drought events have desiccated crop lands, dried up rivers and impacted the changes of Chinese historical dynasties (Chen et al. 2010). Especially since the 1980s, climate-related extreme droughts have increased in frequency, severity, and duration (Ma and Fu 2006; Selvey et al. 2014; Yilmaz et al. 2014). The drought in 1994 in the middle and lower reaches of the Yangtze River resulted in losses of Chinese Yuan Renminbi (CNY) 20 billion. The Yellow River experienced 222-days and 700-km length of drying up in 1997,

Jie Zhang

gs-zhangjie@163.com

1 Key Laboratory of Meteorological Disaster, Ministry of Education (KLME)/Joint International Research Laboratory of Climate and Environment Change (ILCEC)/ Collaborative Innovation Center on Forecast and Evaluation of Meteorological Disasters (CIC-FEMD), Nanjing University of Information Science and Technology, Nanjing 210044, China

2 Institute of Arid Meteorology, China Meteorological Administration, Lanzhou 730020, China drying durations in the year was the longest period since 1949 (Ma and Fu 2006; Zhang et al. 2015). The Huaihe River has also dried up for 122 days in 1999; meanwhile, the most of regions in northern China have suffered consecutive winter-spring and summer-autumn droughts. During the 2000s, drought events have occurred in northern China in the consecutive 4 years (Zhang et al. 2015). These events indicate that extreme droughts are more frequent in northern China, it should be paid more attention.

Drought relates to water supply and loss, therefore, it is linked with precipitation, temperature, evaporation, etc. Based on them, four categories of drought indexes (meteorology, agriculture, hydrology, and socioeconomics) are produced and widely used (Tebaldi et al. 2006; Orlowsky and Seneviratne 2012; Sillman et al. 2013a, b). The most common precipitation-related drought indexes on meteorology were used, which include the precipitation anomaly percentage (Zhang and Zhou 2015), the standardized precipitation index (McKee et al. 1993), the composite drought index (Zou and Zhang 2008; Zhang and Zhou 2015) and the effective drought index (Byun and Wilhite 1999); the Palmer drought severity index (Palmer 1965; Dai et al. 2004) relates to precipitation and other climatological conditions, and it could exhibit drought conditions over East Asia. In 
addition to those indexes, the consecutive dry-day (CDD) is critical for assessment of extreme drought (Orlowsky and Seneviratne 2012; Sillman et al. 2013a, b). The threshold and advantage of these indexes on extreme drought are listed in Table 1. Most of them have been evaluated over East Asia.

Previous studies document that weak Asian monsoon circulation has leaded to increasing drought frequency in northern China (Zhang and Zhou 2015), due to less water vapor toward northern China, but excessive moisture convergence over the Yangtze River along $30^{\circ} \mathrm{N}$, forming the 'south flood and north drought' pattern (Wang 2001; Yu et al. 2004). Drought in northern China is also related to water vapor transported by the western Pacific subtropical high (WPSH, Zhou and Yu 2005), as a primary member of the EASM systems. Beside, some subtropical and tropical circulation also impact extreme drought, that is related to Indian and Pacific sea surface temperature (SST) anomalies, such as the El Niño/Southern Oscillation (ENSO, Huang et al. 2007; Wu et al. 2009), a dominant teleconnection defined as the Pacific-Japan (PJ) pattern (Nitta 1987), with a cyclone anomaly along the Yangtze River and Huaihe River, and an anticyclone anomaly over northern China in midsummer in drought years. On the decadal scale, the weakening EASM is driven by the phase transition of the Pacific Decadal Oscillation (PDO, Song and Zhou 2014), a long-lived El Niño-like pattern of Pacific climate variability.

Extratropical westerly anomalies, including the Siberian high, the blocking high, the subtropical jet stream, etc. (Zhang et al. 2017), impacts extreme-drought related factors in northern China, such as decreased precipitation intensity, increasing temperature, evaporation (Zhang and Zhou 2015), because northern China is located in both the transition zone of monsoon and westerly. From anomaly of stationary wave perspective, it is proved to be responsible for extreme droughts. Schubert et al. (2014) examined the role of stationary Rossby waves on the summertime variability of the extratropics climate in the Northern Hemisphere, and found that the most of extreme climate events are associated with particular recurring Eurasian teleconnection pattern (EU) (first defined by Wallace and Gutzler 1981; Barnston and
Livezey 1987), such as the European heat wave in 2003 and Russian heat waves in 2010. As an EU wavelike structure, the Silk Road pattern (SRP) is recurrent in the Eurasian summer (Enomoto et al. 2003), and it propagates along the subtropical jet stream (Ding and Wang 2005; Zhang et al. 2017).

A few forcing sources are critical for the westerly circulation and wave anomaly, as well as extreme climate. The North Atlantic Oscillation (NAO) can modulate the extratropical atmospheric circulation system, a positive NAO in late spring-summer and PDO could lead to a northward shift in EU pattern and subtropical jet stream in summer, as well as the precipitation area in northern China (Gong and Ho 2003; Li et al. 2008). This phenomenon appears in the severe drought events in 2010/2011 (Sun and Yang 2012). A triode pattern of North Atlantic SST related to NAO could excite a wave train that finally leads to anomalous circulation and drought (Wu et al. 2012). Coupled with the triode pattern of North Atlantic SST, meridional SST pattern over North Pacific, Tibetan Plateau heating could enhance the Eurasian pattern (Zhang et al. 2017). The meridional pattern of Tibetan Plateau heating contributes to a meridional shift in the subtropical jet stream (Zhang et al. 2015), that adjusts the waveguide position of jet stream and snow depth over Tibetan Plateau in spring, further adjusts EASM and summer droughts in the Yangtze River and northern China (Sun and Yang 2012). In addition, many other factors such as decreasing North Arctic ice loss and the summer Arctic Oscillation (AO) pattern lead to an anticyclone anomaly around Lake Baikal and northern China (Zhang et al. 2015).

Previous studies mainly focused on inter-annual extreme drought and drought cases analysis. Do these drought events link to anomalous decadal drying? What is the difference between multi-scale droughts and their mechanisms? It is critical to explore multi-scale droughts for improving model simulation and prediction of drought.

The paper is organized as follows. The data and the drought indexes are introduced in Sect. 2. Section 3 introduces anomalous atmospheric circulation and stationary Rossby wave, and the mechanism of forcing source impacting on wave anomaly. In Sect. 4, a summary is provided.

Table 1 Information of the climate-related extreme drought indexes

\begin{tabular}{llll}
\hline Label & Description & Advantage & $\begin{array}{c}\text { Extreme } \\
\text { drought classifi- } \\
\text { cation }\end{array}$ \\
\hline PA & Precipitation anomaly percentage & Precipitation anomaly & -80 or less \\
PDSI & Palmer drought severity index & Water supply and demand & -4.0 or less \\
SPI & Standardized precipitation index & Short and long term water supply & -1.99 to -1.60 \\
CDI & Composite drought index & Different time-scale & 22.4 or less \\
EDI & Effective drought index & Can determine drought onset and end dates & -2 or less \\
CDD & $\begin{array}{l}\text { Consecutive dry days, maximum number of consecutive } \\
\text { days with less than 1 mm of precipitation }\end{array}$ & $\begin{array}{c}\text { Reflect decrease in precipitation duration and dry- } \\
\text { ing degree }\end{array}$ & 90 th percentiles \\
& & &
\end{tabular}




\section{Data and methods}

Three datasets are used here: the reanalysis dataset is the Interim (ERA-Interim) monthly data (http://apps.ecmwf .int/datasets/) from 1979 to 2016 from the European Center Medium-Range Weather Forecasting (ECMWF), with a horizontal resolution of $0.75^{\circ} \times 0.75^{\circ}$ (Dee et al. 2011). Diurnal observational precipitation data in summer (JJA) from 356 weather stations in northern China are obtained from the China Meteorological Administration website (http://cdc.cma.gov.cn/home.do), which contains 55-years data from 1961 to 2015, 24 stations from 356 stations are rejected due to discontinuous or moving stations, and 332 stations are selected. Multi-model simulations datasets of Coupled Model Intercomparison Project 5 (CMIP5) with representative concentration pathways (RCP) 4.5 scenarios are used for analyzing the effect of Eurasian heating on the wave and circulation anomaly with global warming.

The drought index in this study is defined as the duration length of CDD (i.e., days with precipitation less than $1 \mathrm{~mm}$ ) between two rainfall processes. It is different from Sillmann's (2013a) definition. The CDD not only reflects precipitation frequency but also links to intensification of evaporation. It directly relates to the water supply and loss; therefore, it is a good index for reflecting drought. Because of different circulation impacting on northern China in summer, along with advancing in monsoon circulation, the droughts in the early summer (JJ, June and July) and midsummer (JA, July and August) are respectively analyzed. Drought is defined as CDDs above the 80th percentile in the base period of the JJ/JA for 55-years from 1961 to 2015 , so as to keep at least one case appearing in every year, and extreme drought is defined as the 75th percentile among the drought series, which is equivalent to CDDs above the 95 th percentile during the same period. The reason to use the percentile method is to avoid inhomogeneity at the beginning and end of the base period (Zhang et al. 2005). Drought frequency is the rate of occurrence with CDDs above the 80th percentile compared to all CDD occurrences. Drought intensity is the rate of total CDDs above the 80th percentile compared to the drought frequency during the base period.

In addition, the statistical method empirical orthogonal function (EOF) is used for climate division; and other methods including singular value decomposition (SVD), regression and correlation are used for exploring the linkage of circulation with anomalies of SST and land heating. The wave activity flux is calculated according to the method from Takaya and Nakamura (2001, defined as TNF thereafter), it is used for investigation of energy conversion and transportation.

\section{Results on the extreme droughts}

\subsection{Drought character}

Given that different circulations dominate northern China, with various topography and vegetation types, therefore, it is heterogeneous distribution of precipitation, temperature and evaporation, that leads to complex drought distribution. To contrast the spatial and temporal distribution of extreme drought, an EOF analysis of the anomaly CDDs in JJ and $\mathrm{JA}$ is carried out, respectively, according to eigenvalue zero to divide subarea. The first 7 EOF modes explain 90.4 and $87.9 \%$ of the total variance in JJ and JA, according to these modes, the JJ CDDs in northern China are divided into 8 subareas labeled A-H, shown in Fig. 1, the subareas in JJ are the same as which in JA (ignored). The A subarea stands for Northeast China, the B subarea stands for the central and east China, the $\mathrm{C}$ subarea stands for the lower reaches of the Yangtze and Huaihe Rivers, the D subarea stands for the middle reaches of the Yangtze River, the E subarea stands for the eastern Tibetan Plateau and upper reaches of the Yangtze River, and the F, G and $\mathrm{H}$ subareas stand for northwest China, belonging to the arid-semiarid climate region (Huang et al. 2016a, b).

Because of the domination of EASM circulation and westerly circulation, summer climate variability in northern China exhibits clear difference. To contrast the effect of different circulations on droughts, the CDDs in the early summer (June 1st to July 15th) and the midsummer (July 15th to August 31st) are separately investigated. The reason is that drought in northern China (except the $\mathrm{C}-\mathrm{E}$ subareas, Yangtze and Huaihe River valleys) is mainly dominated by westerly circulation in the early summer; however, during the midsummer, drought in that parts is possibly dominated by both westerly circulation and EASM circulation (Zhang et al. 2018). Figure 2 shows the frequency of CDDs higher than the 80th percentile in the early summer, including the duration, intensity and

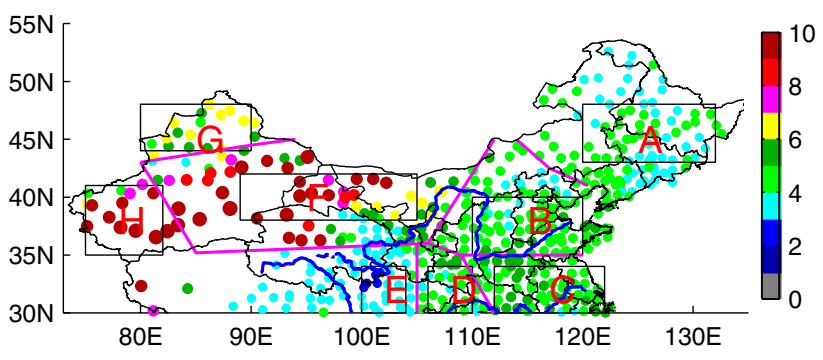

Fig. 1 Distribution of average CDD duration in JJA in northern China and subareas by EOF analysis, the boxes represent the regions of eight subareas. Color dots are the averaged CDD 

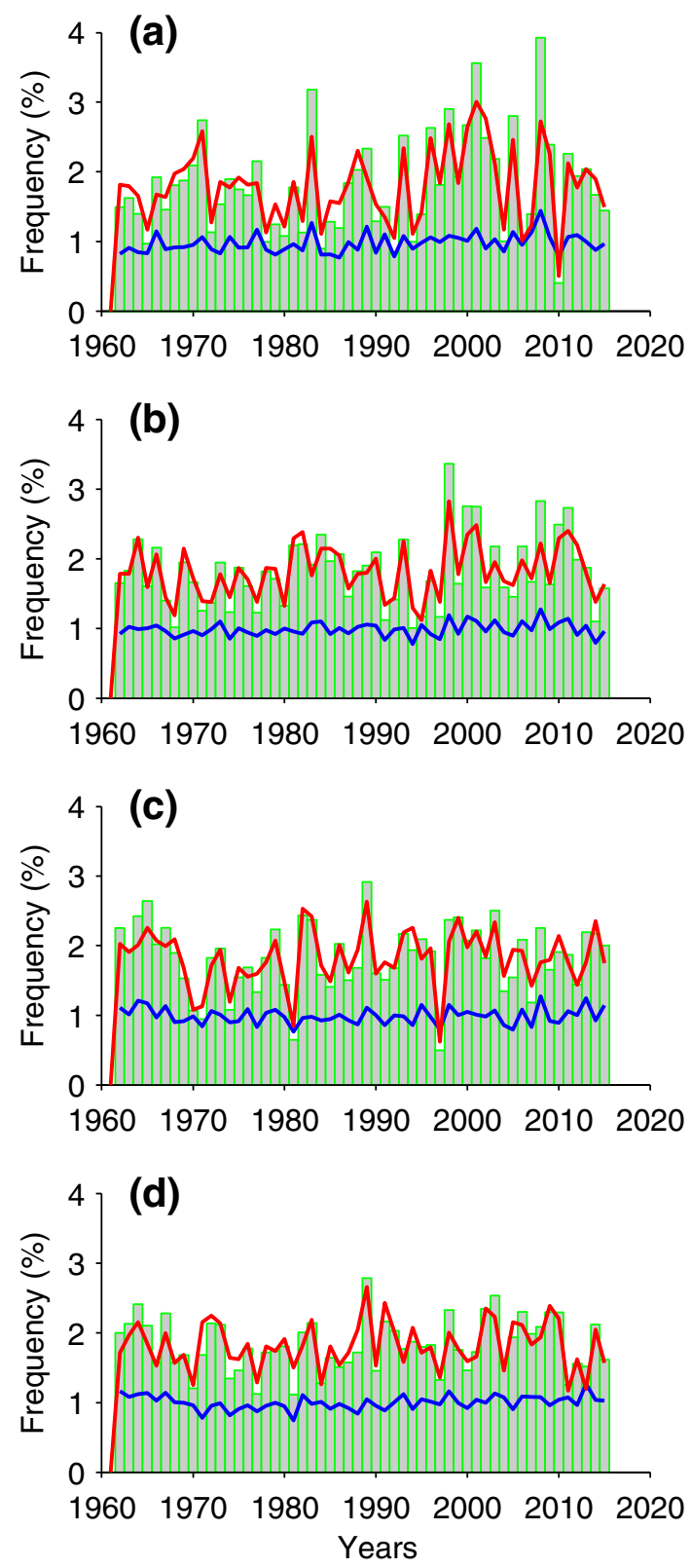
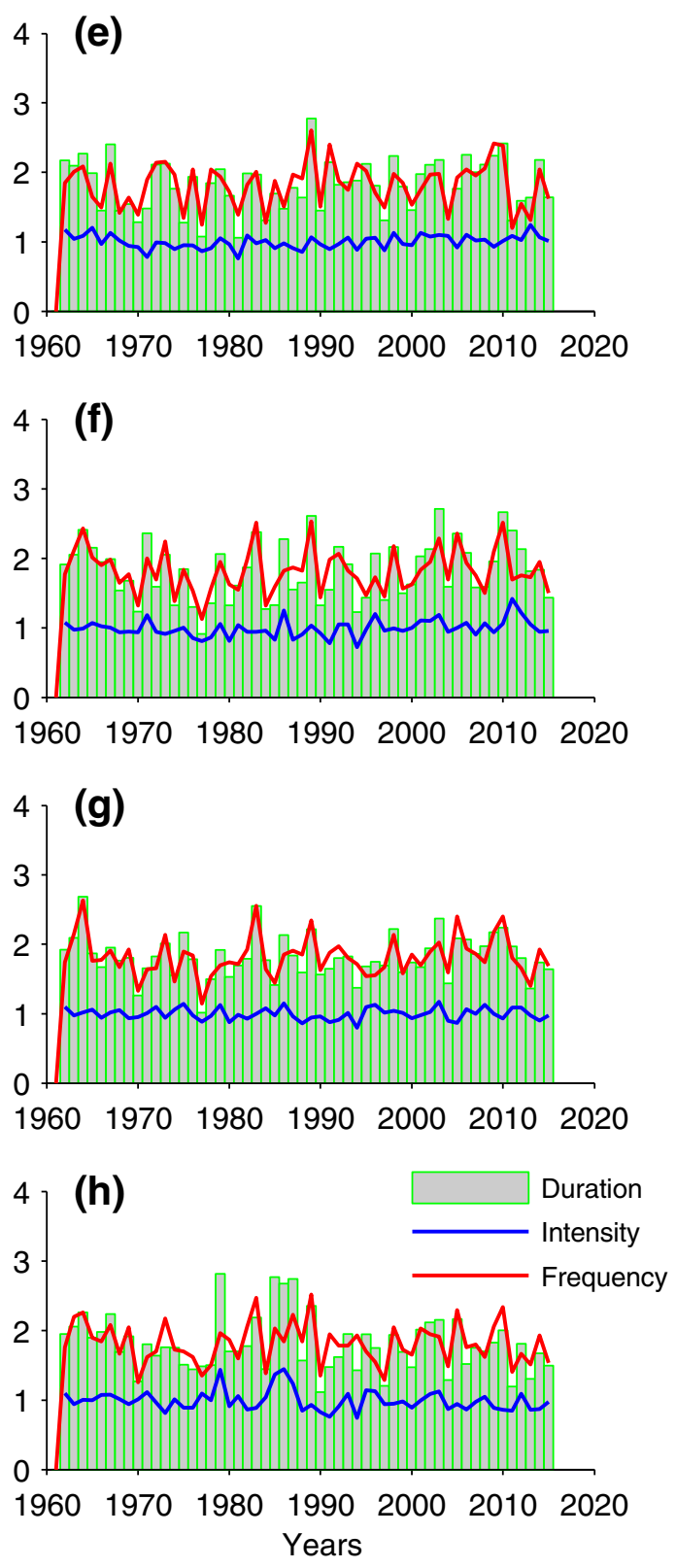

Fig. 2 The frequency distribution of drought duration (histogram), intensity (blue line) and numbers (red line) during the early summer (June 1st to July 15th). The drought events are defined as CDD higher than the 80th percentile

frequency numbers, all of which exhibit the temporal variable of extreme droughts. The figure shows that the drought frequency, duration and intensity are higher after 1990 than before in the subareas A-F, especially from 1994 to present, with $95 \%$ significant confidence level, while they show stability in the other subareas $(\mathrm{G}-\mathrm{H})$ in northwest China. The variation trends of CDD frequency in northern China are consistent with the results from the other indexes ( $\mathrm{Ma}$ and $\mathrm{Fu}$ 2006). Increasing in drought events and intensity after 1990 is associated with anomalous westerly circulation in the region $\mathrm{A}, \mathrm{B}$ and $\mathrm{F}$, because no EASM appears in those regions in the early summer.

Figure 3 shows the frequency of CDDs higher than the 80th percentile in midsummer, including the duration, intensity and frequency numbers. As with CDDs in the early summer, the CDD frequency, duration and intensity in midsummer in the A, B and D subareas are increasing; however, the high frequency distribution is different between the early summer and midsummer: the A subarea exhibits high 

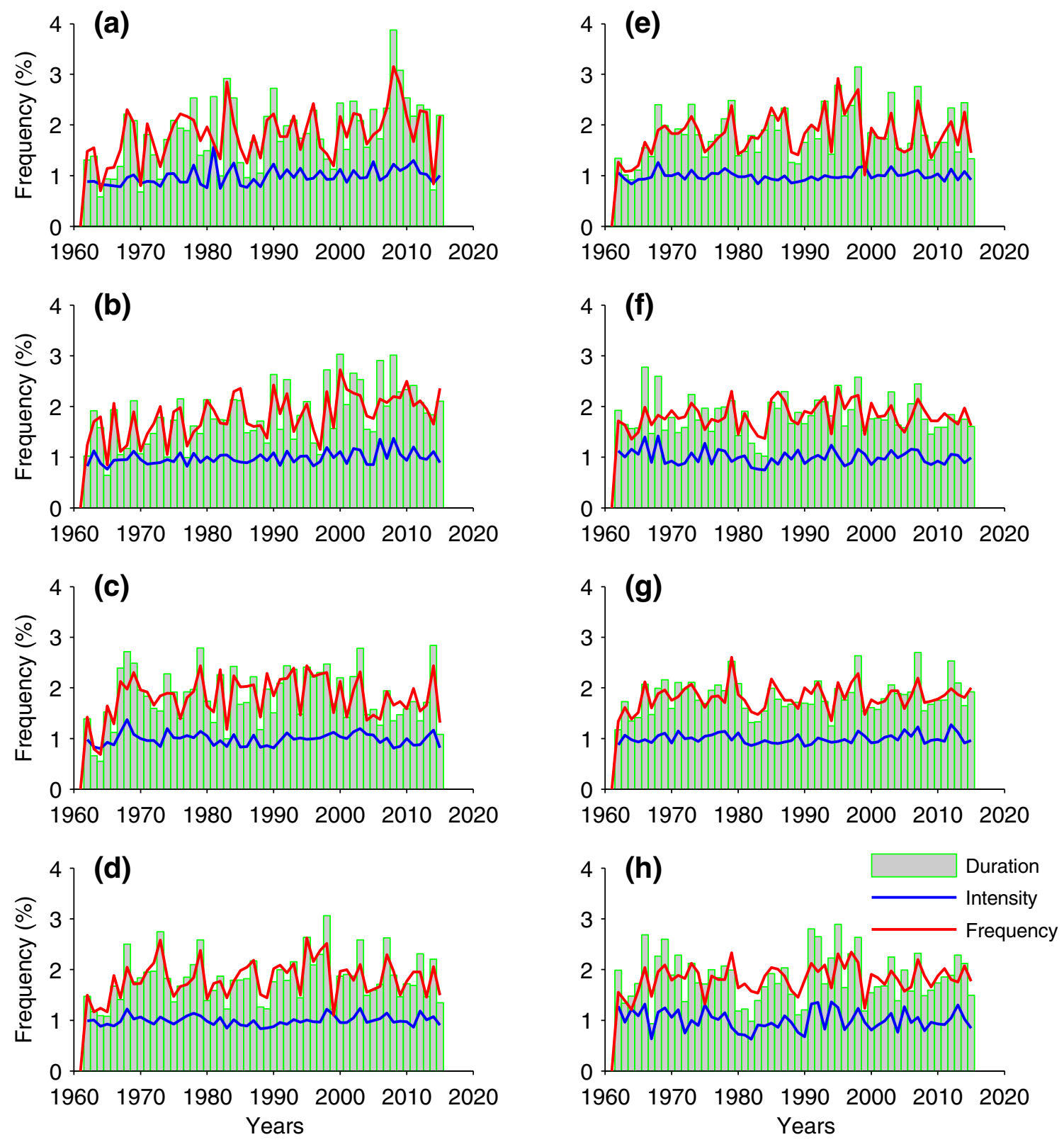

Fig. 3 The frequency distribution of drought duration (histogram), intensity (blue line) and numbers (red line) during the midsummer (July 16th to August 31st). The drought events are defined as CDD higher than the 80th percentile

duration frequency after 2000; the B subarea exhibits high duration frequency after 1997; the C, D, E, F and G subareas exhibit high duration frequency during the 1990s; and the $\mathrm{C}$ subarea shows a decrease in intensity and frequency after 2000. The D and E subareas show a coincident trend. which is impacted by the Indian summer monsoon (Goswami and Ajaya Mohan 2001). The F, G and $\mathrm{H}$ subareas in northwest China show no obvious trend. These difference indicate different cause of drought in midsummer that are related to the EASM and Indian summer monsoon in the south subareas, including the $\mathrm{C}, \mathrm{D}$, and $\mathrm{E}$ subareas, as well as the coupling effects of EASM and westerly circulation in the northern subareas, including the A, B and F. Comparing Fig. 2 with Fig. 3, it can be found that high frequency of droughts exhibits an inter-decadal-scale distribution, although there are inter-annual differences, especially for the northern subareas, including the A, B and F subareas, which indicates that both the EASM and the westerlies are critically important for the multi-scale droughts in northern China.

To further reflect the temporal distribution of extreme drought, the largest CDD series during two stages (the early summer and midsummer) are plotted in Fig. 4, and 

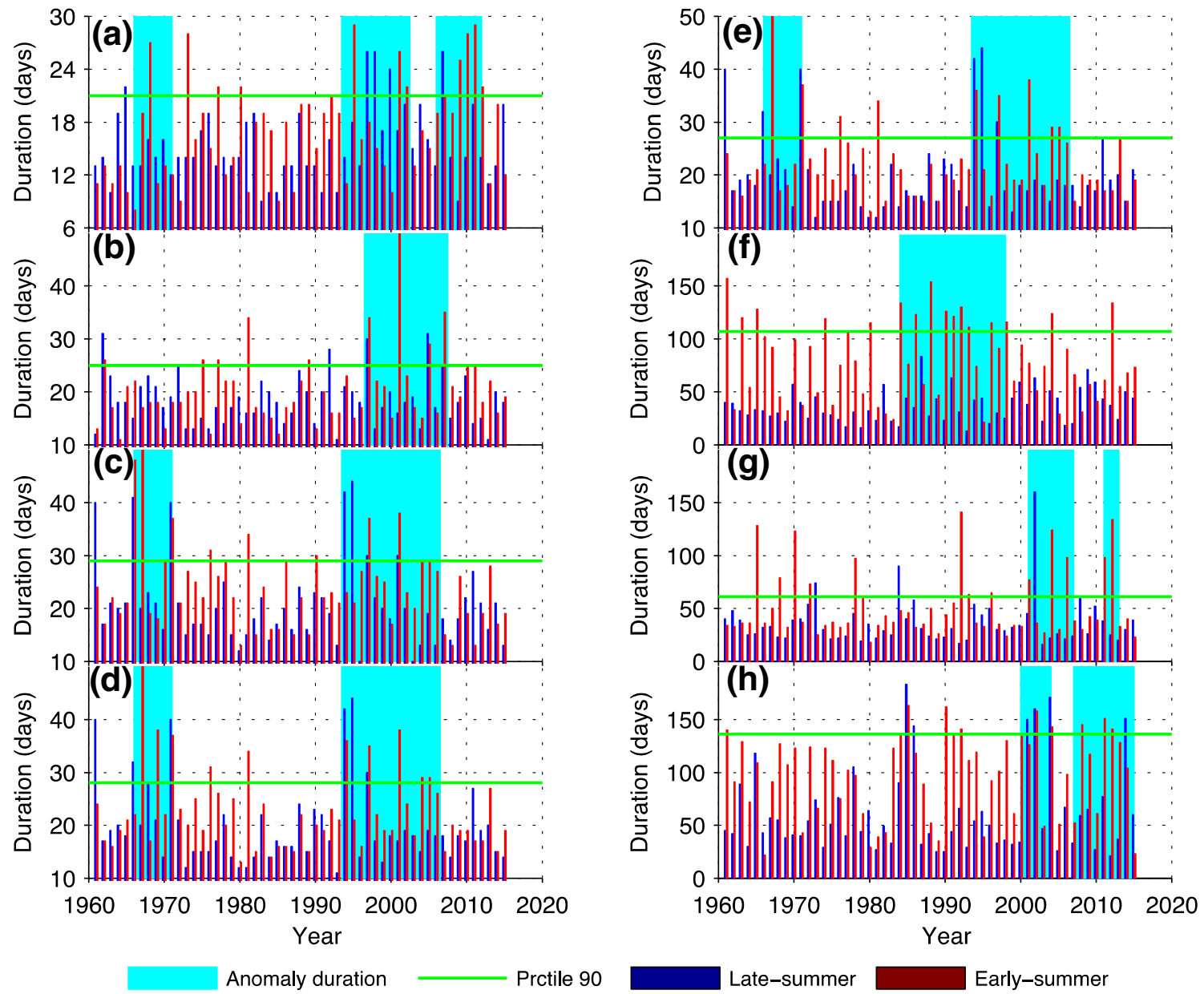

Fig. 4 The temporal series of maximum CDD during two periods (histogram) and the 90th percentile of them during both periods (green thick line)

the threshold with the 90th percentile of the largest CDD is plotted. Values above the threshold correspond to extreme drought. The time series of CDDs shows that extreme drought in subarea A occurred in 1968, 1973,1995, 2001, 2002, 2009, 2010 and 2011 during the early summer, with the longest dry duration of 29 days in 1995; during midsummer, extreme drought occurred in 1965, 1997, 1998, 2000 and 2007, with the longest dry duration of 26 days in 1997. Extreme drought in subarea B occurred in 1981, 1997, 2001, 2005 and 2007 during the early summer, with the longest dry duration of 50 days in 2001; during midsummer, extreme drought occurred in 1962, 1992, 1997 and 2005 , the longest dry duration was 31 days in 1962. Extreme drought in subarea C occurred in 1966, 1967, 1971, 1981, 1997 and 2001 in the early summer, with the longest dry duration of 50 days in 1967; during midsummer, extreme drought occurred in 1961, 1966, 1971, 1994, 1995, 1997 and 2001, with the longest dry duration of 44 days in 1995. Extreme drought in subarea D occurred in 1967, 1969, 1971, 1976, 1981, 1994, 1997, 2001, 2004 and 2005 during the early summer, with the longest dry duration of 50 days in 1967; during midsummer, extreme drought occurred in 1961, 1966, 1971, 1994, 1995 and 1997, with the longest dry duration of 44 days in 1995. Extreme drought in subarea E occurred in 1967, 1971, 1976, 1981, 1994, 1997, 2001, 2004 and 2005 during the early summer, with the longest dry duration of 50 days in 1967; extreme drought occurred in 1961, 1966, 1971, 1994, 1995 and 1997 during midsummer, with the longest dry duration of 44 days in 1995. Extreme drought in subarea F occurred in 1961, 1963, 1965, 1974, 1984, 1986, 1988, 1990-1993, 1996, 1998, 2004 and 2012 during the early summer, with the longest dry duration of 157 days in 1961; no extreme drought occurred during midsummer. Extreme drought in subarea G occurred in 1965, 1968, 1970, 1972, 1978, 1992, 2001, 2004, 2006, 2011 and 2012 during the early summer, with the longest dry duration of 141 days in 1992; extreme drought occurred in 1973, 1984 and 2002 during midsummer, with the longest dry duration of 160 days in 2002. Extreme drought in subarea $\mathrm{H}$ occurred in 1961, 1985, 1990, 1992, 2002, 2004, 2008, 
2011 and 2012 during the early summer, with the longest dry duration of 163 days in 1985; extreme drought occurred in 1985, 1986, 2001, 2002, 2004 and 2014 during midsummer, with the longest dry duration of 183 days in 1985 . The summer extreme drought years and descriptions are in Table 2. Extreme drought occurred in 1961, 1968, 1972, 1981, 1992, 1994, 1997, 2000, 2001, 2009 and 2010, with the longest dry duration larger than 50 days. The drought events from 1997 to 2010 are the most severe and influential; the drought events from 1966 to 1972 are also severe. The top years in terms of the maximum dry duration are 2001, 2002 and 1997. These extreme drought periods are coincident with the drought period shown in Figs. 2 and 3, showing that extreme droughts exhibit inter-decadal distribution. Two decadal periods around the 1970s' and after the 1990s' deserve attention. Kim et al. (2011) consider that extreme droughts during the stages of 1967-1969 and 1994-1996 are mainly caused by consecutive shortages of summer rainfall, the extreme event occurred in northern China, Japan and the Korean Peninsula (Lee et al. 2012).

\subsection{Atmospheric circulation and wave activity flux anomaly related to extreme droughts}

Given that drought is impacted by both westerly circulation and monsoon circulation in JA, we select July to explore drought related circulations, and the contributions of different circulations are also contrasted. Extreme drought events in 2000, 2001, 2002, 2006, 2010, 2011 and 2014 are selected, because droughts in these years is notable in July, that spanned in the early summer and midsummer, and those cases reveal a decadal drought background of the twenty-first century. The synthesis of the anomalous 500$\mathrm{hPa}$ geopotential height and flow field in July is shown in

Table 2 Drought years over northern China from 1961 to 2015. The events were obtained from the appendix table of Zhang and Pan (2009), Zhang et al. (2015) China Weather Network

\begin{tabular}{|c|c|c|c|c|c|c|c|c|c|}
\hline Year & A & B & $\mathrm{C}$ & $\mathrm{D}$ & $\mathrm{E}$ & $\mathrm{F}$ & G & $\mathrm{H}$ & Impacts \\
\hline 1961 & & & $\sqrt{ }$ & $\sqrt{ }$ & $\sqrt{ }$ & $\sqrt{ }$ & & $\odot$ & A $16 \times 10^{4} \mathrm{~km}^{2}$ drought area \\
\hline 1962 & $\sqrt{ }$ & $\begin{array}{l}\odot \\
\sqrt{ }\end{array}$ & & $\odot$ & $\odot$ & $\odot$ & $\odot$ & & More than 200 drying days \\
\hline 1966 & & & $\odot$ & $\sqrt{ }$ & $\sqrt{ }$ & & & & Severe drought in Yangtze river \\
\hline 1968 & $\odot$ & $\begin{array}{l}\odot \\
\sqrt{ }\end{array}$ & & & & & $\odot$ & $\sqrt{ }$ & $13.3 \times 10^{4} \mathrm{~km}^{2}$ drought area \\
\hline 1971 & & & $\odot$ & $\begin{array}{l}\odot \\
\sqrt{ }\end{array}$ & $\begin{array}{l}\odot \\
\sqrt{ }\end{array}$ & & & & More than 35 drying days in the southwest parts \\
\hline 1972 & $\stackrel{\odot}{\sqrt{ }}$ & $\odot \sqrt{ }$ & $\stackrel{\odot}{\sqrt{ }}$ & $\sqrt{ }$ & $\sqrt{ }$ & $\sqrt{ }$ & & & The lower reaches of the Huanghe River dried up for 20 days \\
\hline 1981 & $\odot$ & $\odot$ & $\odot$ & $\odot$ & $\sqrt{ }$ & $\odot$ & & & Most of region in Northern China \\
\hline 1992 & & $\sqrt{ }$ & & & $\sqrt{ }$ & $\odot$ & $\odot$ & $\odot$ & Losses of at least CNY 9 billion \\
\hline 1994 & & & $\sqrt{ }$ & $\odot$ & $\stackrel{\odot}{\sqrt{ }}$ & $\sqrt{ }$ & & $\sqrt{ }$ & Losses of CNY 20 billion \\
\hline 1995 & $\odot$ & & $\sqrt{ }$ & $\sqrt{ }$ & $\sqrt{ }$ & & & & $13 \%$ reduction of output in the northwest China \\
\hline 1997 & $\sqrt{ }$ & $\begin{array}{l}\odot \\
\sqrt{ }\end{array}$ & $\begin{array}{l}\odot \\
\sqrt{ }\end{array}$ & $\begin{array}{l}\odot \\
\sqrt{ }\end{array}$ & $\begin{array}{l}\odot \\
\sqrt{ }\end{array}$ & $\sqrt{ }$ & $\begin{array}{l}\odot \\
\sqrt{ }\end{array}$ & $\sqrt{ }$ & The Huanghe River dried up for 222 days; The Huaihei River also dried up for 122 days \\
\hline 1999 & $\begin{array}{l}\sqrt{ } \\
\odot\end{array}$ & $\begin{array}{l}\odot \\
\sqrt{ }\end{array}$ & & & & $\sqrt{ }$ & & & Most parts of Northern China suffered summer-autumn consecutive droughts \\
\hline 2000 & $\sqrt{ }$ & $\odot$ & & & & $\sqrt{ }$ & & & About $40.54 \times 10^{4} \mathrm{~km}^{2}$ experienced spring-summer drought \\
\hline 2001 & $\odot$ & $\odot$ & $\begin{array}{l}\odot \\
\sqrt{ }\end{array}$ & $\begin{array}{l}\odot \\
\sqrt{ }\end{array}$ & $\odot$ & & $\odot$ & $\sqrt{ }$ & Drought-induced disaster area was $38.47 \times 10^{4} \mathrm{~km}^{2}$ \\
\hline 2002 & $\odot$ & $\sqrt{ }$ & $\odot$ & $\begin{array}{l}\odot \\
\sqrt{ }\end{array}$ & & $\begin{array}{l}\odot \\
\sqrt{ }\end{array}$ & $\begin{array}{l}\odot \\
\sqrt{ }\end{array}$ & $\begin{array}{l}\odot \\
\sqrt{ }\end{array}$ & Losses of CNY 100 billion \\
\hline 2004 & $\odot$ & & & $\odot$ & $\odot$ & $\odot$ & $\odot$ & $\begin{array}{l}\odot \\
\sqrt{ }\end{array}$ & Most parts of Northern China suffered spring-summer consecutive droughts \\
\hline 2006 & & & & $\sqrt{ }$ & $\sqrt{ }$ & $\sqrt{ }$ & $\sqrt{ }$ & $\sqrt{ }$ & $1.34 \times 10^{6}$ people suffering shortage of drinking water in the Central and Northern China \\
\hline 2007 & $\sqrt{ }$ & $\odot$ & & & & $\sqrt{ }$ & & & Losses of CNY 78.5 billion \\
\hline 2009 & $\sqrt{ }$ & $\odot$ & & & $\odot$ & $\odot$ & $\odot$ & & 7 provinces suffering drought \\
\hline 2010 & $\odot$ & $\sqrt{ }$ & & & & $\odot$ & & & Drought-induced disaster area was $54.7 \times 10^{4} \mathrm{~km}^{2}$ \\
\hline 2012 & & & & & & $\odot$ & $\odot$ & $\odot$ & Persist drought in spring-early summer \\
\hline
\end{tabular}

$\odot$ represents the early-summer period, $\sqrt{ }$ represents the midsummer period, which are obtained according to CDD 


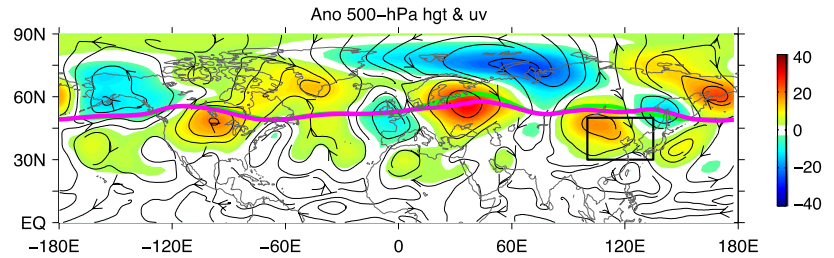

Fig. 5 The 500-hPa geopotential height (shaded, unit: gpm) and flow field anomalies (streamlines) with respect to the 1979-2015 climatology for selected years. The thick pink and green line is long-term mean and anomalous 5580-gpm line in July, respectively. The box is northern China (the study region, it is the same hereafter)

Fig. 5. There are five positively anomalous centers of geopotential heights including the northeast America, northwest Atlantic, northern Europe, southern Lake Baikal to Eastern Japan, Eastern Siberian. Over the high latitudes, the summer AO-mode anomaly with negative center of geopotential height over Kara Sea is clear, extending AO anomaly toward Balkhash Lake is helpful to the northward development of a downstream warm ridge and positive geopotential height around Lake Baikal (Zhang et al. 2015); meanwhile, the weak cyclone anomaly on the southern China shows the weakening WPSH, leading to weak water vapor transported toward northern China (Zhou and Yu 2005), further restraining precipitation in northern China. Figure 5 shows that circulation anomaly mainly exhibits anomalous pattern of westerly teleconnection, which corresponds to extreme droughts. Previous studies suggest that Eurasian droughts are strongly linked to the development of blocking and stationary Rossby waves (e.g., Scaife et al. 2010; Schubert et al. 2014). Specifically, the stationary wave anomaly is an important component of Eurasian temperature and rainfall variability in summer, associated with wave propagation patterns (Ambrizzi et al. 1995; Hoskins and Woollings 2015), such as the wave anomaly related to the European heat wave in 2003 and Russian heat wave in 2010 (Schubert et al. 2014). Therefore, stationary wave anomaly is worth exploration, because it will lead to amplitude, E-W location and $\mathrm{N}-\mathrm{S}$ location change of stationary wave. To quantitatively describe westerly teleconnection pattern and stationary wave anomaly, we expect that the leading of anomalous meridional wind in July in Fig. 6 would be tied to different wave patterns. Given that teleconnection pattern is clearer over the mid-high latitude than that over the mid-latitude, we perform the leading meridional wind separately $\left(40^{\circ} \mathrm{N}-80^{\circ} \mathrm{N}, 20^{\circ} \mathrm{N}-60^{\circ} \mathrm{N}\right.$, representing highlatitude and mid-latitude, respectively). Figure 6 shows that the first EOF mode over the high-latitude clearly exhibits a wavelike structure, with notable EU pattern, that approximately extends across northern Atlantic via the west coast of Europe and northern Eurasia. The wave pattern from the Ural Mountains to Japan is similar to the Eurasian-Pacific teleconnection pattern in winter and spring discovered by

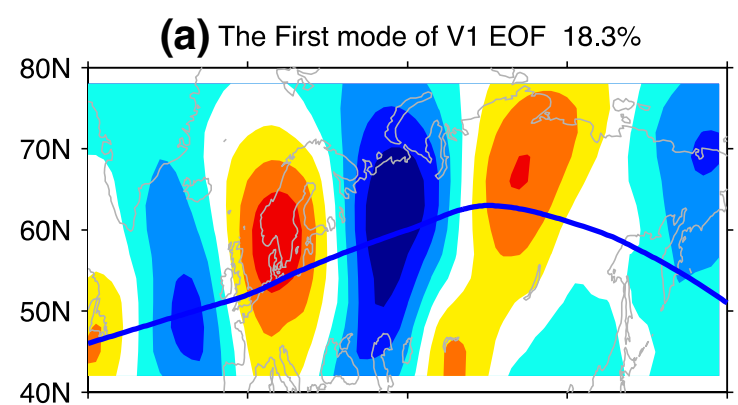

(b) The First mode of V2 EOF $17.1 \%$

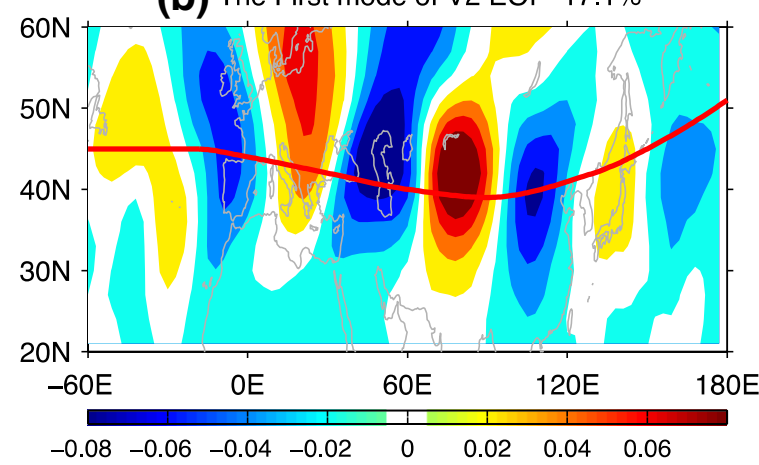

Fig. 6 The first leading EOFs of the 200-hPa v-wind anomalies in July of 1979-2015 in two regions (a, b) and normalized leading principal components (PCs) and 10-year moving-average filter (c, d).

\section{(c) PC1 of V1 EOF}

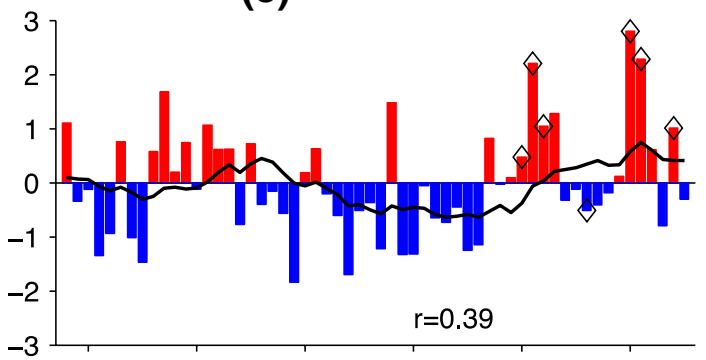

(d) PC1 of V2 EOF

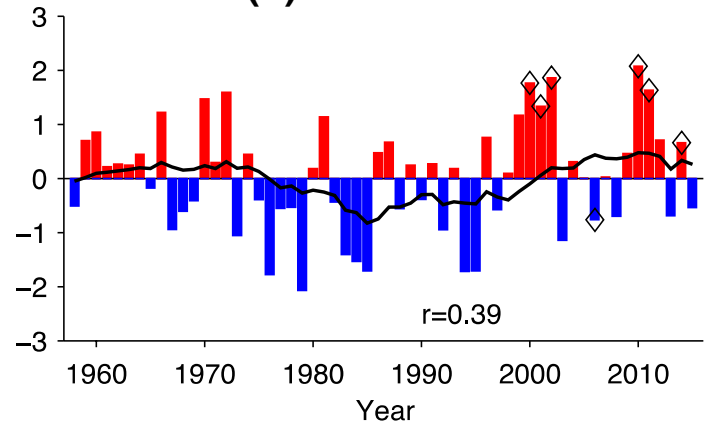

Units are arbitrary. The thick blue and red color-line (a, b) represents EU and SRP wave tracks from $\frac{\partial \nu^{\prime}}{\partial x}$ (Zhang et al. 2018). Diamond symbols stand for drought years, it is the same hereafter 
Gutzler (Wallace and Gutzler 1981). It is very similar to the actual 200-hPa v-wind anomalies in July in 2001, 2002, 2010 and 2011 . The variance of the first mode is $18.3 \%$. The EOF mode over the mid-latitude clearly shows a midlatitude SRP wavelike structure (Lu et al. 2002). There is an obvious signature, with a split branches over the west coast of Europe, the northern component extends across Eurasia to the polar front jet over the high latitude, which likes the EU pattern, the southern component approximately extends across northern Atlantic via the west coast of northern Europe downward to Caspian Sea, and eastward to northern China. This pattern is a waveguide mode along the subtropical jet stream, which is possibly forced by Indian monsoon heating and a propagation of stationary waves along the Asian jet in the upper troposphere (Enomoto 2004; Ding and Wang 2005). It is very similar to the actual 200-hPa v-wind anomalies in July in 1999, 2000, 2009 and 2010. The variance of the first mode is $17.1 \%$. Sato and Takahashi (2006) identified a southern Eurasian wave extending eastward that impacts Japan in JJA, this wave section could be seen in Fig. 6b. Under the coupling of Tibetan Plateau heating with meridional SST gradient in the North Pacific and the North Atlantic, this wavelike structure is helpful to developing a circumglobal forced wave (Zhang et al. 2018). EU and SRP tracks (blue and red line) are plotted in the Fig. 6.

Corresponding to EOF modes, the principal components (PCs) show multi-scale distribution, and the decadal change is clear (Fig. 6c, d). From 1973 to 1995, EU/PC and SRP/PC exhibit a decadal negative trend, which is helpful to weakening and out-of-phase wave anomaly of the EU and SRP pattern. Before 1973 and after 1995, EU/PC and SRP/PC show a positive phase, which is helpful to enhancing inphase wave mode.

To explore the contribution of EU and SRP wave pattern to atmosphere circulation, the regression of $500-\mathrm{hPa}$ geopotential height and horizontal wind vector to the EU/PC and SRP/PC are showed in Fig. 7. The regressed geopotential height and flow field exhibit clear EU pattern and SRP pattern. EU regression exhibits 3-wavenumber distributions, with three positive centers over northern Atlantic, northern Europe, and Eastern Siberia to East Asia; two negative centers are over the west coast of Europe, and Kara Sea to the mid-Siberia. On the south of $40^{\circ} \mathrm{N}$, it is positive geopotential height with a positive center over North Africa. Above positive/negative regressions past significant confidence level of $95 \%$. SRP regression exhibits 4-wavenumber distribution over the mid-latitude, with four positive centers over northern Atlantic, North Africa to the west of Ural mountain, northern China to eastern Siberia and North Pacific, two negative centers along SRP are over southern Europe and Central Asia, another negative center is along the coast of Kara Sea. The correlation of EU and SRP with vorticity over northern China is -0.42 , and -0.3 , respectively, indicating the possible relation of them.

Regression of geopotential height over northern China indicates that enhanced EU pattern and SRP pattern after 1995 contribute to coincident anticyclone over northern China, which is helpful to enhancing ridge around Lake Baikal and northern China, that finally results in descending motion and divergence, further contributes to persistent dry days and prolonging CDD. In addition, weak WPSH also leads to weak water vapor transported to northern China, which also contributes to dry days. Therefore, extreme
Fig. 7 The temporal correlation between $500-\mathrm{hPa}$ geopotential height (shaded), wind vectors in July and the first leading PCs of 200-hPa meridional wind anomaly for the period 1979-2015, showed in Fig. 6. The black dot is the 95\% significance confidence level

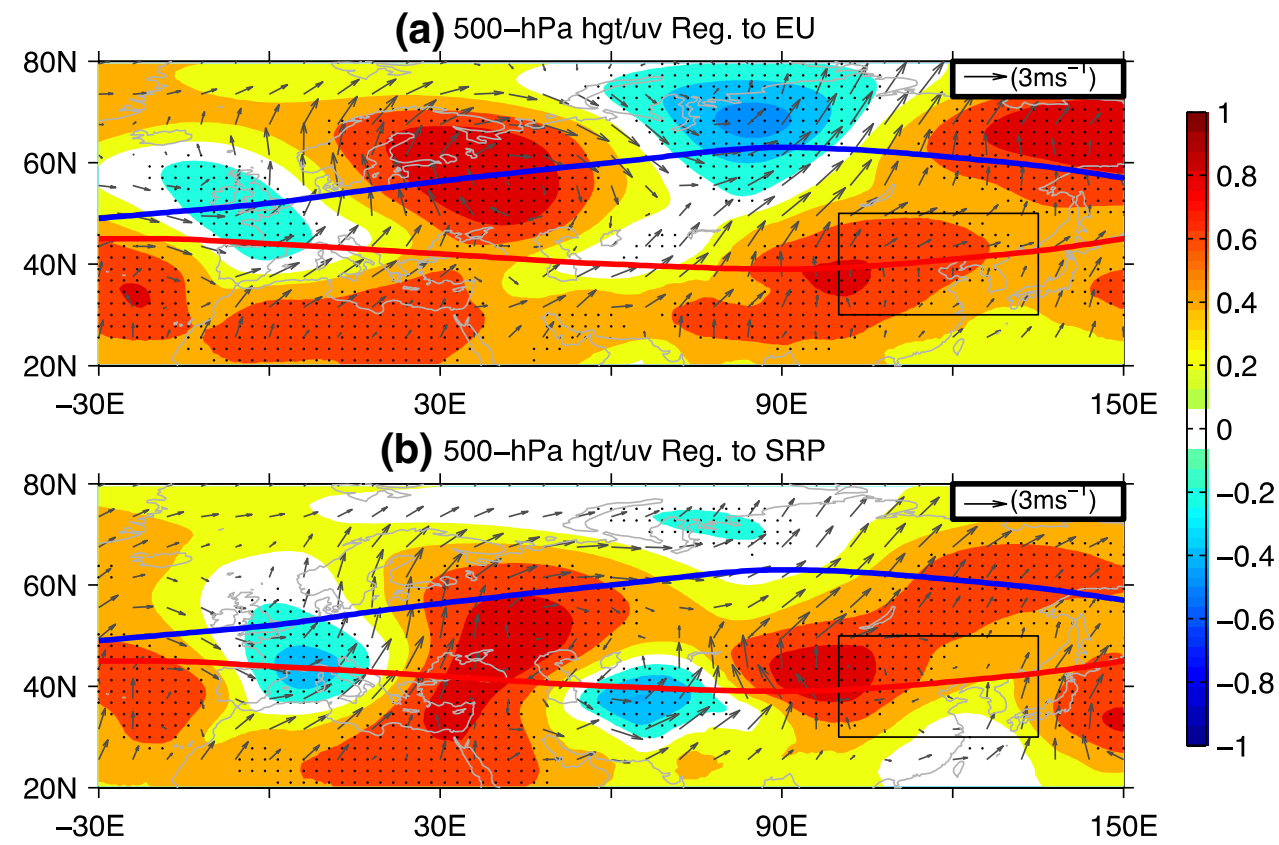


droughts in northern China possibly have response to multiwave patterns along the subtropical jet stream, polar front jet, etc. Enhancing EU and SRP is imposed on stationary waves, it is the key dynamic contributions to anomalous atmospheric circulation in the mid-latitudes (Petoukhov et al. 2016). However, the key question is why the wave train becomes strong or in-phase. What is the key factor leading to enhancing EU and SRP wave pattern?

\subsection{The relation of Eurasian heating with atmospheric circulation and wave pattern}

To verify the EU and SRP wave pattern propagating via northern China, and forcing sources of EU and SRP wave anomaly. The composite of 300- and 500-hPa TNF, TNF divergence and vertical TNF in those drought years are shown in Fig. 8. The anomalous TNF clearly displayed that the wave energy propagated eastward between $40^{\circ} \mathrm{N}$ and $75^{\circ} \mathrm{N}$, and there are two divergent TNF centers over northern Eurasia and eastern Siberia. Those are the possible sources of wave energy production and energy conversion. The TNF propagates along the subtropical jet stream, sub polar jet and the EU and SRP wave. A convergent TNF exists over the east of Ural Mountains, the west and east of Lake Baikal and northern China, which is helpful to strengthening in the east Ural ridge, the west-ridge and east-trough around the Lake Baikal and northern China. In addition, a divergent TNF over the Lake Baikal leads to a weakening trough over Lake Baikal, which signifies eastward shift of west-ridge and east-trough around Lake Baikal. This result interprets the anomalous anticyclone over northern China in Fig. 5. A positive upward TNF could instruct whether wave energy is from the lower troposphere, which closed relates to boundary forcing; it is the most remarkable over northern Siberia, that propagates along EU wave showed in Figs. 6 and 7, and provides energy for EU pattern. The TNFs at $300-$ and $500-\mathrm{hPa}$ are coincident with each other. Figure 8c shows 500-hPa vertical TNF, the positive vertical TNF just occurs over those divergence centers, with one center over northern Eurasia, and the most obvious centers over Europe, which indicates that energy from the lower troposphere and surface in those centers providing major energy for TNF divergence, and Europe and northern Eurasia are the major forcing sources of anomaly wave. Certainly, other forcing sources such as the west coast of northern Europe are worthy of attention because it is the general wave source related to
Fig. 8 Composite of TNF (vector) and TNF divergence (shaded) at $300 \mathrm{hPa}$ (a) and $500 \mathrm{hPa}(\mathbf{b})$ as well as vertical TNF (shaded, c) in the drought years (a) 300-hPa TNFxy-Div

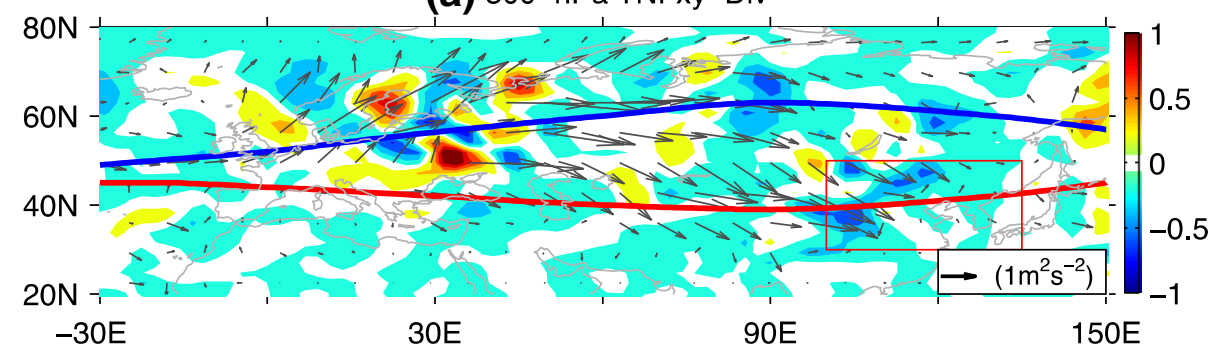

(b) 500-hPa TNFxy-Div

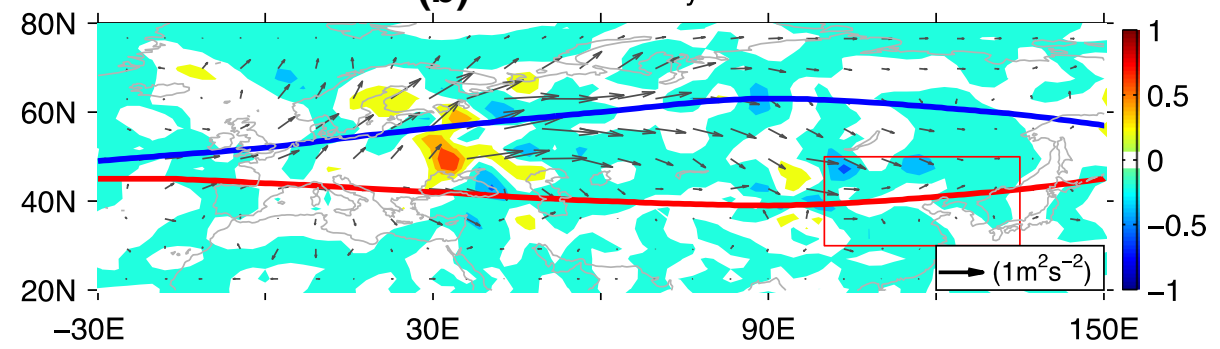

(c) Ano 500-hPa TNFz

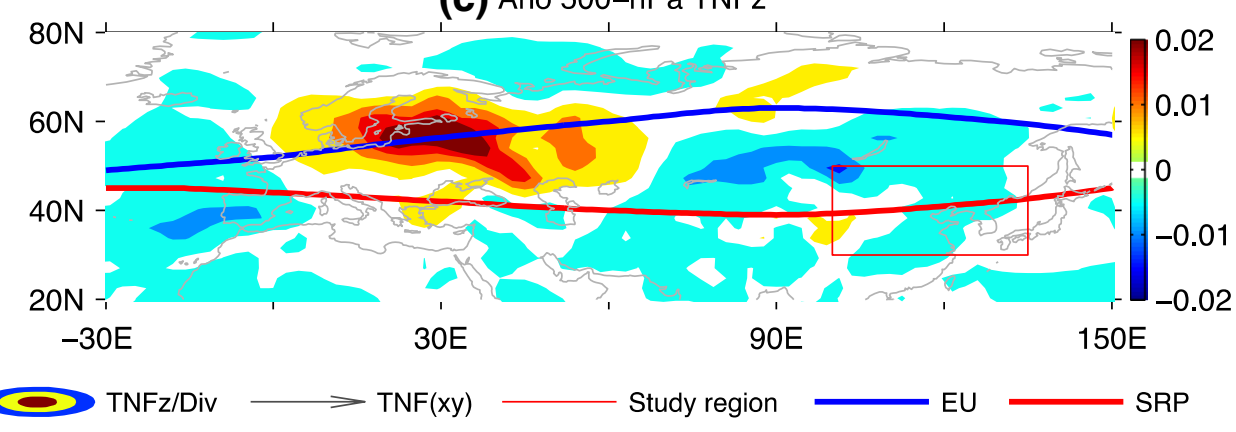


North Atlantic SST pattern (Wu et al. 2012). Above TNF corresponds to EU and SRP forced wave, however, what are the key factors that enhancing TNF over Europe and northern Eurasia? To answer this question, the key source of TNF and forcing source should be further verified.

Given that the Europe and northern Eurasia are the most major wave sources according to above TNF analysis, the study explores the vertical TNF over the Eurasia $\left(30^{\circ} \mathrm{N}-80^{\circ} \mathrm{N}, 10^{\circ} \mathrm{W}-150^{\circ} \mathrm{E}\right)$ at the $500-\mathrm{hPa}$ level (Fig. 9), and the first and second leading modes by EOF analysis are showed. It shows that the most regions of northern Eurasia exhibit positive anomaly, and the large center appears along the north coast of northern Eurasia, and the largest center is along the west coast of northern Europe. The first mode of vertical TNF corresponds to the most of TNF divergence in Fig. 8, its variance is $38.9 \%$. The PC1 in Fig. 9c, corresponding to the first mode of vertical TNF, exhibits increasing trend, with negative anomaly before 1995 and positive anomaly after 1995, which shows increases of the first mode of positive TNF, and northern Eurasia will be a significant forcing source providing more energy for forced wave; in addition, 1995 is also the time when the AMO changed to its warm phase (Qian et al. 2014), indicating the linkage of TNF change with Atlantic SST pattern. The second mode exhibits wavelike distribution of vertical TNF (Fig. 9b), the variance is $8.2 \%$, with interannual scale, and it is positive in those drought years (Fig. 9d).

(a) The First mode of TNz EOF $38.9 \%$

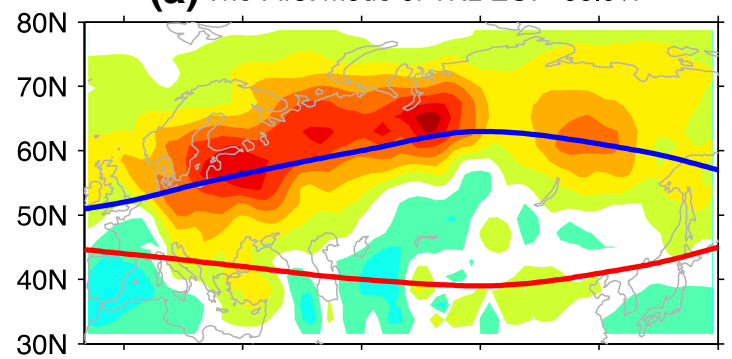

(b) The Second mode of TNz EOF $8.2 \%$

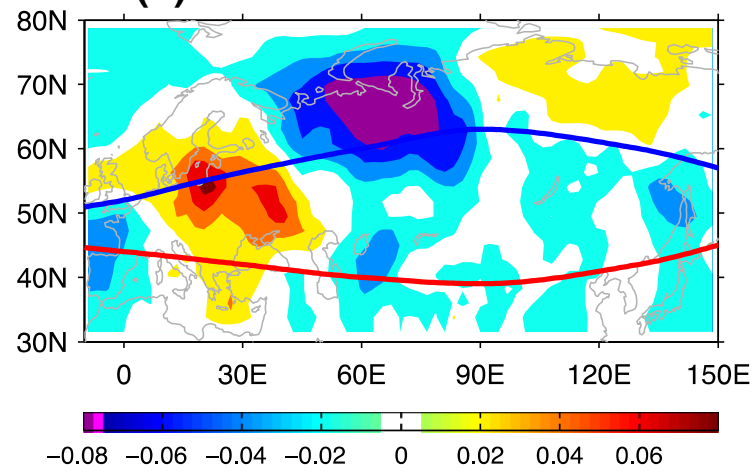

To further explore the relation of increasing TNF with EU and SRP, Fig. 10 shows scatter relations between TN/ PC1 and EU and SRP indexes (Fig. 6c, d). TN/PC1 exhibits positive correlation with EU/PC1 and SRP/PC1, which means that increasing vertical TNF is possibly responsible for increasing EU and SRP.

To further explain TNF contributing to atmospheric circulation through EU and SRP wave, Fig. 11 shows the geopotential height regression to the vertical TNF/PC1. TNF regression exhibits 2 -wavenumber distributions in our study region, with three positive centers over northern Atlantic, northern Europe, and Eastern Siberia to East Asia; two negative centers are over the west coast of Europe and Kara Sea to the mid-Siberia, which is more like EU pattern in Fig. 7a, this pattern is responsible for anticyclone over northern China, that finally results in persistent dry days and prolonging CDD. On the south of $55^{\circ} \mathrm{N}$, the wavelike structure also exhibits SRP pattern, it is the positive geopotential height over Caspian Sea and surrounding regions, Tibetan Plateau to northern China, except for an obvious negative center over Southern Europe, another two negative centers are more south, they are the north edge of Arabian Sea and the west coast of subtropical Pacific, which is helpful to weakening westextending of WPSH. Above positive centers show significant confidence level of 95\%, however, the negative centers are weak a little, except for a center over central Siberia. In all, positive TNF over northern Eurasia possibly results

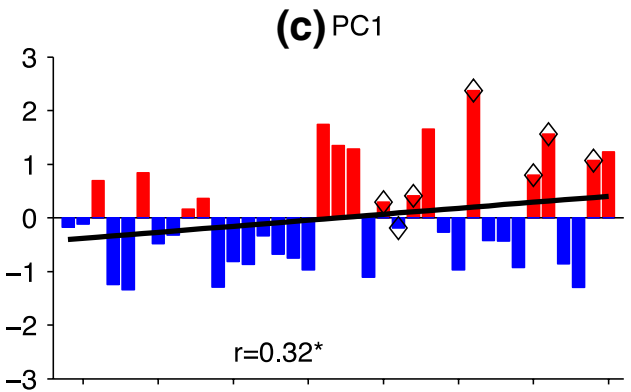

(d) $\mathrm{PC2}$

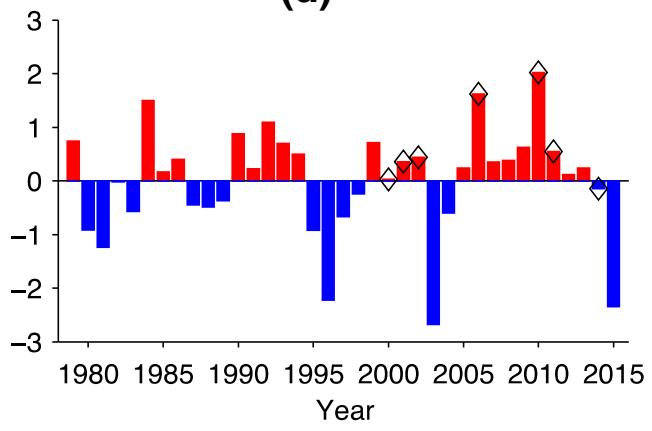

Fig. 9 The first two leading EOFs of the vertical TNF in July 1979-2015 (a, b) and normalized leading PCs (c, d). Units are arbitrary 
(a) TNz \& EU

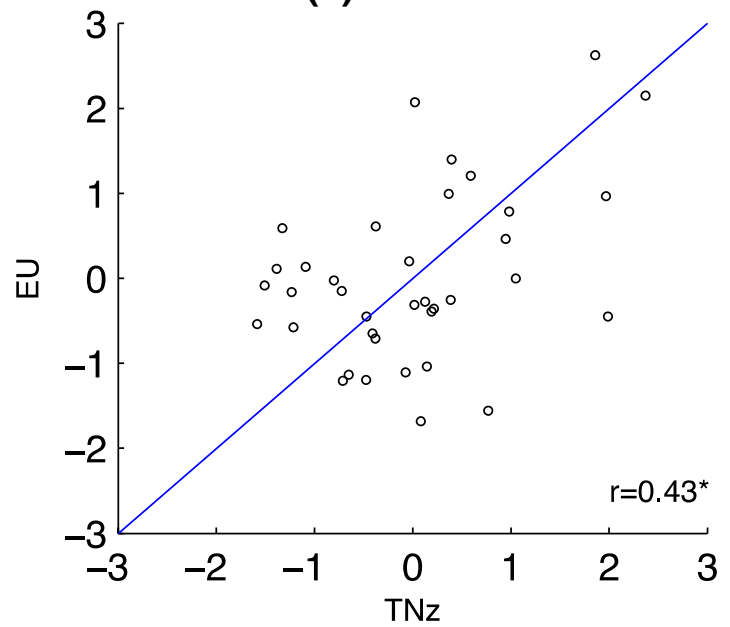

(b) TNz \& SRP

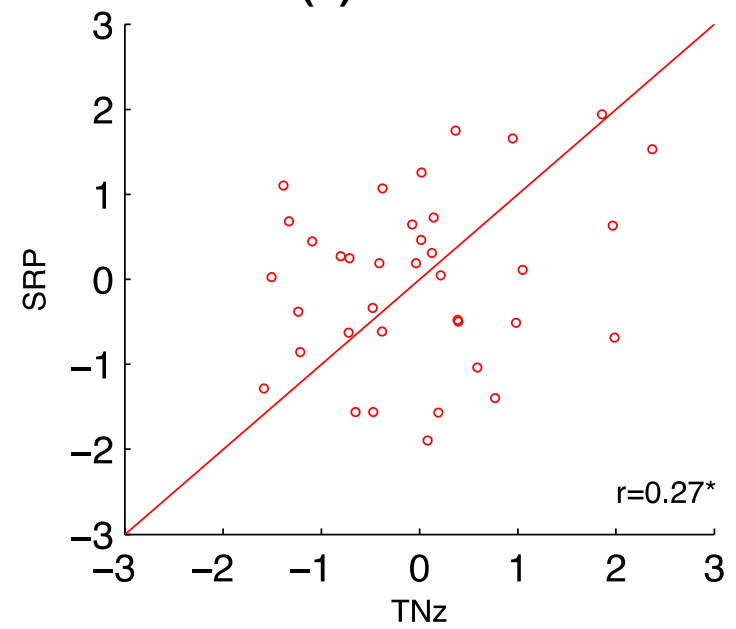

Fig. 10 Scatter relations of the normalized EU (a) and SRP (b) index with the normalized leading PC of vertical TNF (TNz)

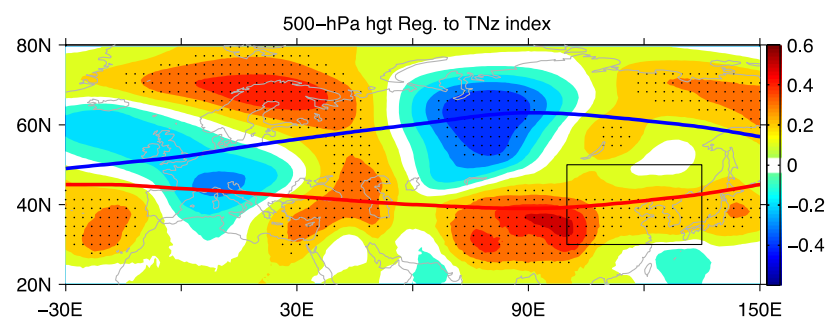

Fig. 11 The regression of 500-hPa geopotential height (shaded) to the normalized leading PC of vertical TNF (TNz). The black dot is the 95\% significance confidence level

in increasing EU and SRP, and finally leads to anticyclone anomaly, persistent dry days and prolonging CDD. This finding is coincident with Burke and Brown (2008) finding of increasing in the global drought in the twenty-first century and a drying tendency in northern China.

\subsection{Physical mechanisms of Eurasian heating on forced wave}

To explore the influence of the Eurasian heating on the increasing TNF over the Eurasia, we estimate energy conversion including the local barotropic energy conversion CK (Hoskins et al. 1983; Simmons et al. 1983) and local baroclinic energy conversion CP (Kosaka and Nakamura 2006).

$$
\begin{aligned}
& C K=\frac{v^{\prime 2}-u^{\prime 2}}{2}\left(\frac{\partial \bar{u}}{\partial x}-\frac{\partial \bar{v}}{\partial y}\right)-v^{\prime} u^{\prime}\left(\frac{\partial \bar{u}}{\partial y}-\frac{\partial \bar{v}}{\partial x}\right) \\
& C P=\frac{f}{\sigma} v^{\prime} T^{\prime} \frac{\partial \bar{u}}{\partial p}-\frac{f}{\sigma} u^{\prime} T^{\prime} \frac{\partial \bar{v}}{\partial p}
\end{aligned}
$$

where $u^{\prime}$ and $v^{\prime}$ are anomaly zonal and meridional wind velocity, respectively; $\bar{u}$ and $\bar{v}$ are the mean zonal and meridional wind velocity, respectively; $T^{\prime}$ is the anomaly temperature; $f$ is the Coriolis parameter; $\sigma=\frac{R \bar{T}}{C_{p} p}-\frac{d \bar{T}}{d p}$ with temperature (T); and the specific heat at a constant pressure $\left(C_{p}\right)$.

Zonal wind anomalies are favorable for inducing CK (Kosaka and Nakamura 2006), which is associated with zonal elongated vorticity anomalies $\left(\left|u^{\prime 2}\right| \gg\left|v^{\prime 2}\right|\right)$ exhibited by the extended Eliassen-Palm flux E (Hoskins et al. 1983):

$E=\left(v^{\prime 2}-u^{\prime 2},-v^{\prime} u^{\prime}\right)$

CK indicates the zonally asymmetric climatological flow, $\mathrm{E}$ and the related items are used for explaining $\mathrm{CK}$ variable in the anomaly drought years. Figure 12 shows $\mathrm{CK}$ and a component of the extended Eliassen-Palm flux E and CP. A positive CK appears over North Atlantic, the Western Europe, Caspian Sea and Central Asia along the SRP pattern and the north flank of the subtropical jet stream. Negative CK appears over the most of the other regions. Such distribution in the Western Europe over the upper troposphere is consistent with which in the lower troposphere, showing deep circulation and energy conversion. As for the CK over the Western Europe (west box), positive CK to the south is related to zonally elongated vorticity anomalies $\left(\left|u^{\prime 2}\right| \gg\left|v^{\prime 2}\right|\right)$, exhibiting westward-pointing E embedded in the exit of a subtropical jet stream $\left(\frac{\partial \bar{u}}{\partial x}<0\right)$. This is same as positive CK over the North Atlantic. As for northern China over the east box, there is a negative CK center, which is related to the anomalous southwesterlies $\left(-u^{\prime} v^{\prime}\right)$ 
Fig. 12 Local barotropic energy conversion CK $\left(10^{-7} \mathrm{~m}^{2} \mathrm{~s}^{-3}\right.$; shaded) and the extended EP flux (arrows with scaling at the right of the panel) at a 300$\mathrm{hPa}$ and b 700-hPa, vertically integrated baroclinic energy conversion $\mathrm{CP}$ at $700 \mathrm{hPa}(\mathbf{c}$, $\mathrm{W} \mathrm{m}{ }^{-2}$ ), and temporal series of the normalized $\mathrm{CK}$ and $\mathrm{CP}$ over the key region (left box) from 700 to $300 \mathrm{hPa}(\mathbf{d})$ (a) 300-hPa CK and extended EP flux

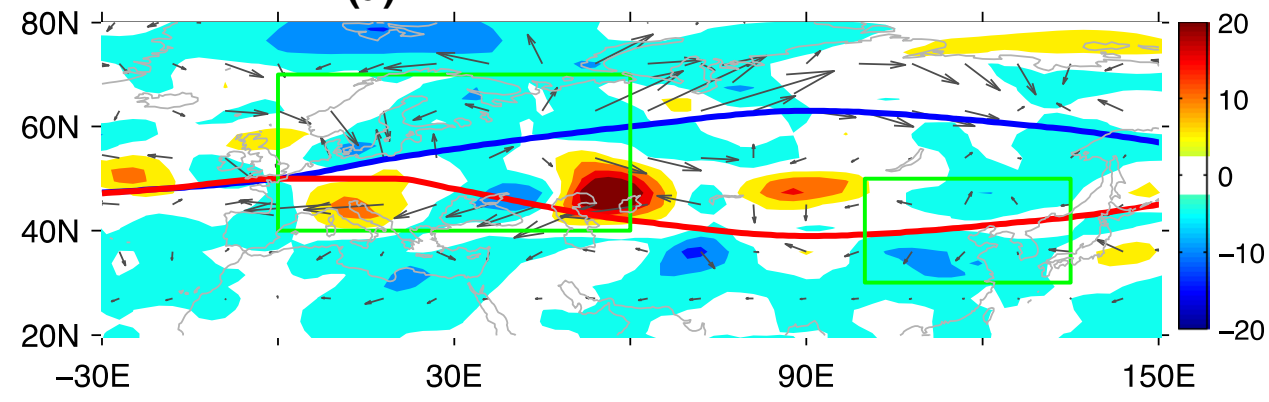

(b) 700-hPa CK and extended EP flux

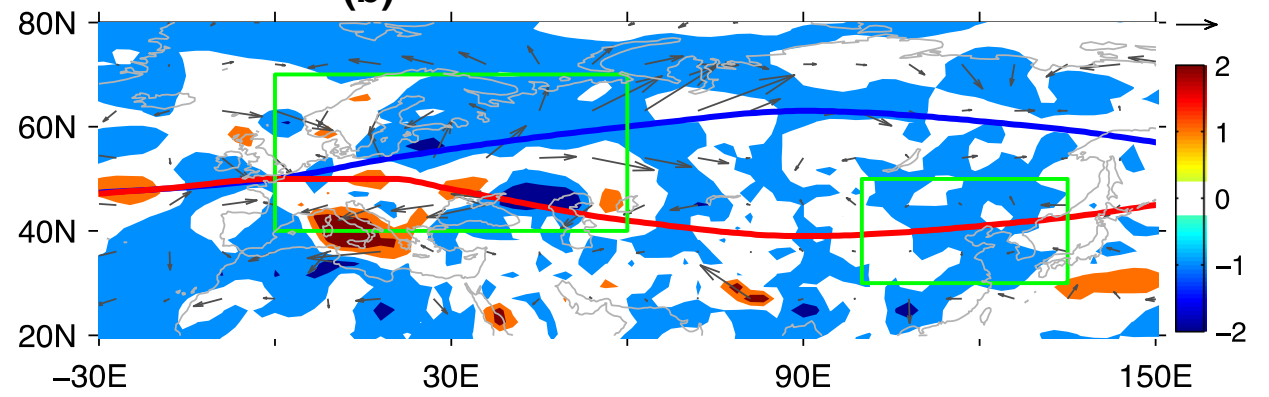

(c) $700-\mathrm{hPa} \mathrm{CP}$

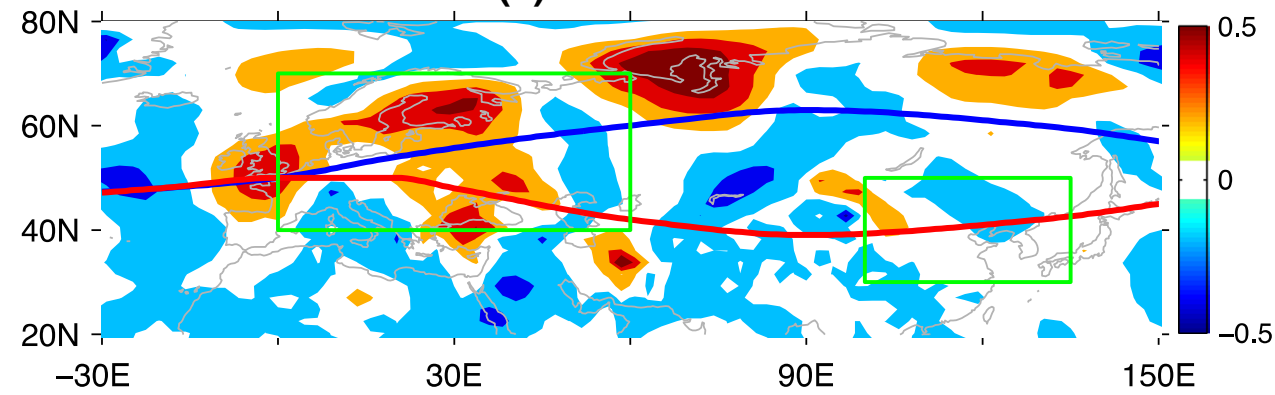

(d) $\mathrm{CP}$ and $\mathrm{CK}$ in the key box

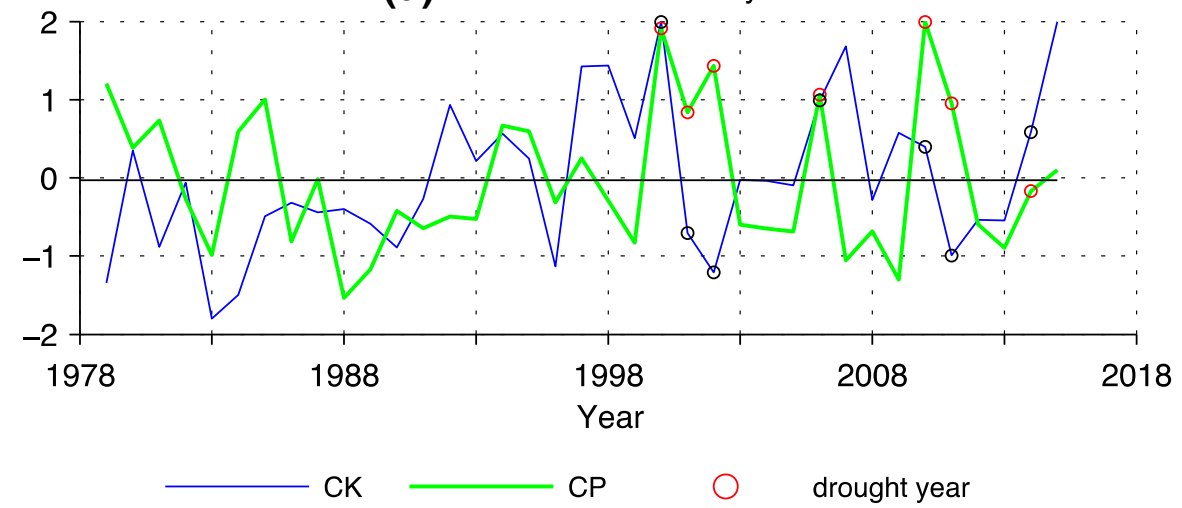

exhibiting southwesterly pointing E, embedded in the south flank of a subtropical jet stream $\left(\frac{\partial \bar{u}}{\partial y}>0\right)$. Positive CK means the conversion of kinetic energy from the mean flow to the composited anomalies, which is helpful to the forced wave. Therefore, the Western Europe to central Asia is one source that induces barotropic wave energy; however, a decrease of wave energy occurs over northern China, it restrains wave energy and trough development and finally leads to the anticyclone anomaly.

A series of positive/negative $\mathrm{CP}$ are associated with Rossby wave propagation and vertical shear along the subtropical jet stream. Three sets of CP centers are found over the Eurasian continent. The positive CP over northern Europe (west box), along Kara Sea and Eastern Siberia, indicates increase in atmospheric baroclinicity energy 
conversion, while a negative $\mathrm{CP}$ occurs over northern China. It links to net effective energy due to diabatic heating including radiative forcing and convective heating. Diabatic heating over Europe can be sensitive to underlying heating. To contrast $\mathrm{CP}$ and $\mathrm{CK}$ between drought years and normal years, Fig. 12d shows the series of normalized CP and CK in the key region, the results indicate that less positive $\mathrm{CK}$ provide energy for anomaly forced wave, reflecting internal variability of atmosphere; however, the positive $\mathrm{CP}$ occurs in the drought years, which leads to increasing energy for forced wave, such significant CP must be influenced by external forcing and diabetic heating. It is hypothesized that Europe to central Asia (west box) and northern Eurasian (other positive CP regions) lead to increasing atmospheric baroclinicity in the troposphere, which is helpful to the energy production exhibited by CP. Together with weak energy transformation exhibited by $\mathrm{CK}$, increasing energy conversion finally leads to a positive perturbation for forced wave and atmospheric circulation. As for northern China, a negative $\mathrm{CK}$ is helpful for kinetic energy transformation from the eddy field to the mean flow, which contributes to an increase subtropical jet stream. However, a negative CP shows weak baroclinic energy conversion from the lower troposphere to the eddy and perturbation, both $\mathrm{CK}$ and $\mathrm{CP}$ over northern China leads to negative energy for the forced wave; therefore, the convergent WAF anomaly should be from external transportation, linked to upstream energy from the northern Eurasia and Europe.

\subsection{The Eurasian heating change with climate warming and contribution to forced wave}

To further reveal the effect of Eurasian warming on anomalous stationary wave and extreme drought, warming simulation is explored. As continental forcing in summer, surface heating is significant for anomaly circulation, multi-model simulations with multi-scenario IPCC/AR4 show that soil moisture globally exhibits severe deficits and frequent droughts (4-6-month duration), with doubling of the spatial extent from the mid-twentieth century to the end of the twenty-first century (Sheffield and Wood 2008). Therefore, it is necessary to reveal extreme drought mechanisms associated with anomaly of the land surface (e.g., local soil moisture and heating).

Surface heating effect on atmosphere related to surface sensible heat flux (defined as hfss) and other diabetic heating factors. Above results show that extreme droughts after 1990s are significant and which just occur during the warming stage, is hfss anomaly over Eurasian continent associated with global warming? It is merit in the section. We employ multi-model simulations of CMIP5 with RCP4.5scenario, because RCP4.5-scenario is close to the scenario in the future 50 years, it is helpful to prediction of extreme droughts.

Figure 13 shows the trend rate of skin temperature (a), hfss (b) and vertical TNF (TNFz, c) in July 2006-2055 (50years) with multi-model simulations and RCP4.5-scenario. The trend rate of skin temperature shows high value along EU and SRP wave, however, in the key region of Europe, the trend rate is lower a little in the west part and higher in the east part. In northern China (study region), the trend rate is lower than other region along EU and SRP. Corresponding to high trend rate of skin temperature, the positive trend rate of hfss is also clear along EU and SRP, and it is the highest region over the key region, northern Europe. The trend rate of TNFz exhibits wavelike distribution along the EU and SRP, the positive TNFz along SRP corresponds to positive trend rate of hfss and high rate of skin temperature over southern Europe, central Asia and northern China; the positive TNFz along EU corresponds to positive rate of hfss and high trend rate of skin temperature over northwest Europe, along Kara Sea and northeast Asia. It indicates that positive TNF has response to increasing hfss and skin temperature with global warming.

To illustrate the Eurasian heating effect on TNF anomaly, we perform a SVD analysis between TNFz and hsff over Eurasian continent. The results, shown in Fig. 14, demonstrate that the first SVD (SVD1) mode of hfss is similar to the trend rate of skin temperature, with positive anomaly along EU and SRP, and the highest value is over the key region. In the SVD1 of TNFz, the negative/positive pattern is similar to trend rate of $\mathrm{TNFz}$, with significant wavelike structure along EU and SRP. This indicates that positive hfss over the key region is helpful to the wavelike TNFz, the key region is regarded as a significant forcing source. The first SVD mode of detrended hfss is the wavelike pattern along the EU, however, wavelike pattern is unclear along SRP. In the SVD1 of detrended TNFz, the wavelike pattern is similar to hfss over other regions along EU, but it is reverse over part regions. The finding indicates the Eurasian heating is responsible for positive $\mathrm{TNFz}$, and it is more significant with global warming, which provides energy for forced wave, as well as increasing extreme events before 2055. In addition, SVD results also indicate land-air interaction over Eurasian continent.

\subsection{Summary and conclusions}

This study shows that extreme droughts have occurred on the decade scale during the recent 60 years, the extreme droughts occurred in 1961, 1972, 1981, 1986, 1992, 1994, 1997, 2000, 2001, 2005-2007 and 2010, with the most severe and influential drought period after the 1990s, and the second period with severe drought from 1960 to 1972. The study also identified a significant relationship between the 
Fig. 13 The trend rate of skin temperature (a), hsff (b) and vertical TNF (c) variability in July 2006-2055 (50 years) with multi-model simulations of CMIP5 and RCP4.5-scenario (a) Ts

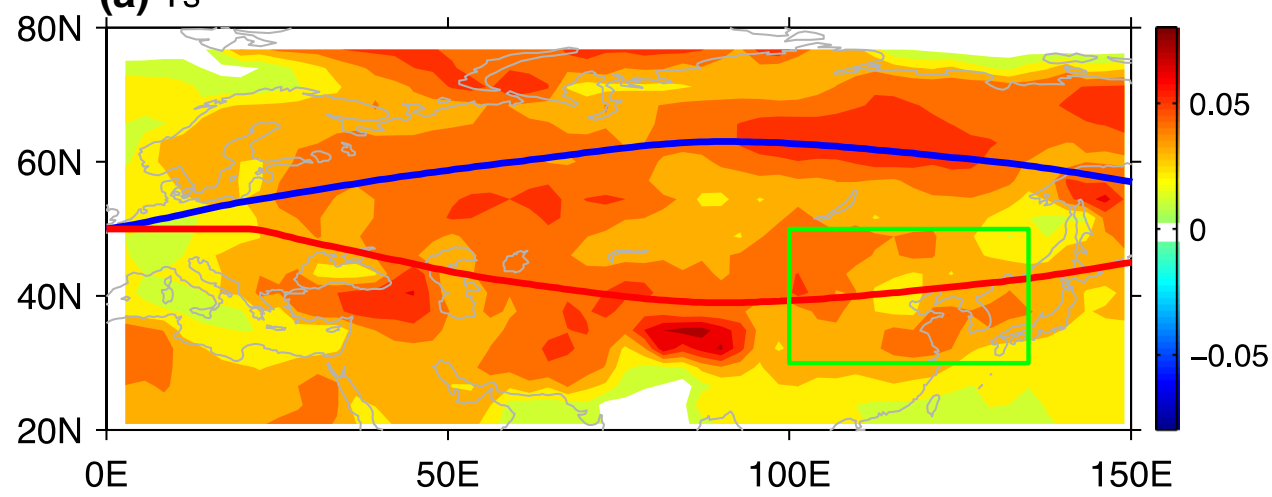

(b) hfss
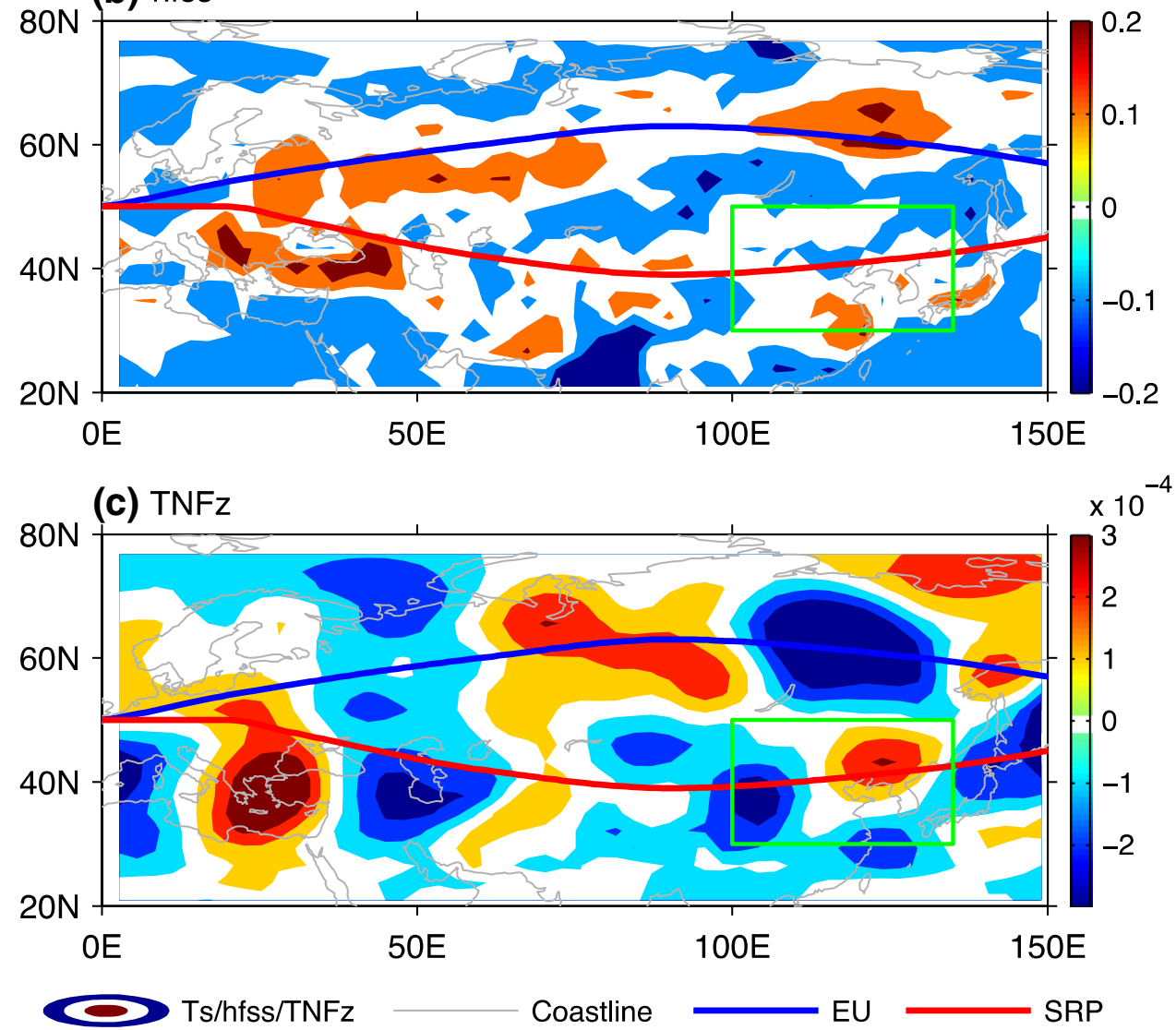

extreme droughts on the decade scale over northern China and a persistent anticyclone around Lake Baikal, as well as an enhancing EU and SRP wave pattern.

Positive anomalies of EU and SRP pattern after 1995 contribute to coincident anticyclone, and enhancing ridge around Lake Baikal and northern China, that finally results in downward motion and divergence, and contributes to persistent and prolonging CDD. In addition, weakening WPSH also leads to weak water vapor transported to northern China, contributing to prolonging CDD, which is related to positive SRP. All these anomalies have response to increasing vertical TNF over the Europe and northern Eurasia.
Europe and northern Eurasian are the significant forcing sources. Europe and northern Eurasian heating leads to increasing atmospheric baroclinicity in the lower troposphere, which is helpful to the energy production exhibited by increasing $\mathrm{CP}$, together with weak energy transformation exhibited by $\mathrm{CK}$, increasing energy conversion finally leads to an enhancing in forced wave. It is more notable with global warming, which will leads to increasing in Europe and northern Eurasian heating and extreme events before 2055. In addition, anthropogenic input related to global warming also plays complementary roles in shaping the monsoon and thereby drought changes in China (Song et al. 
(a) hfss SVD1 (99\%)

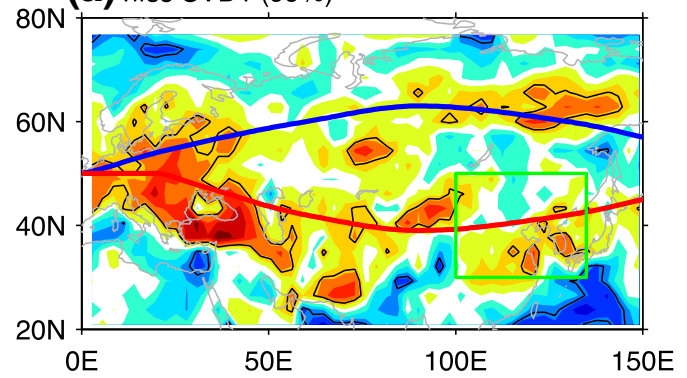

(C) Detrended hfss SVD1 (16.5\%)

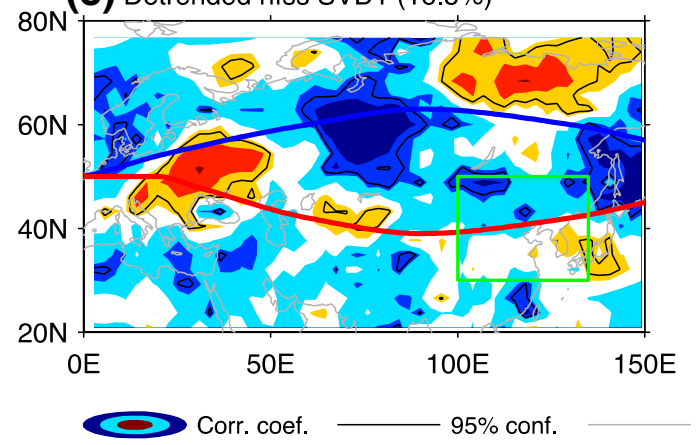

(e) Standard hfss PC1

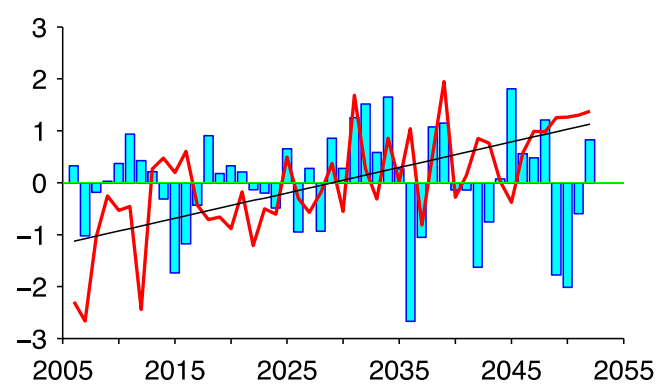

detrended hfss/TNFz $\longrightarrow$ hfss/TNFz

Fig. 14 Heterogeneous correlation map of the first mode of SVD for hfss in Eurasia (a) and 500-hPa vertical TNF (b), the first mode of SVD for detrended hfss (c) and detrended 500-hPa vertical TNF (d), normalized leading PC1 of hsff (red line) and detrended hsff (e)

2014; Menon et al. 2002). Above studies mainly explain the linkage of global warming with extreme droughts, related to both monsoon circulation and westerly circulation.

Decadal anomaly of water transportation over northern China is linked to subtropical circulation, Qian and Zhou (2014) highlighted that approximately $70 \%$ of the drying trend during 1960-1990 related to negative PDO phase changes, which drives the EASM declining trend with an inter-decadal variability (Zhou et al. 2008). Low frequency change of SST not only links with moisture transfer, but also relates to wave pattern like PJ pattern and SRP pattern. In addition, Francis and Vavrus (2012) suggest that the (b) TNFz SVD1

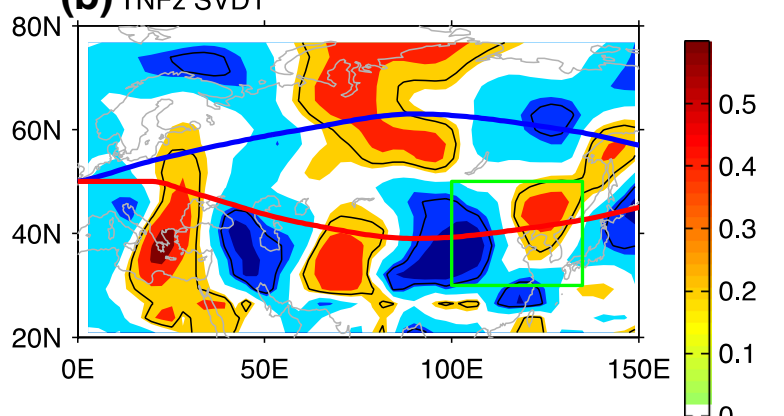

(d) Detrended TNFz SVD1

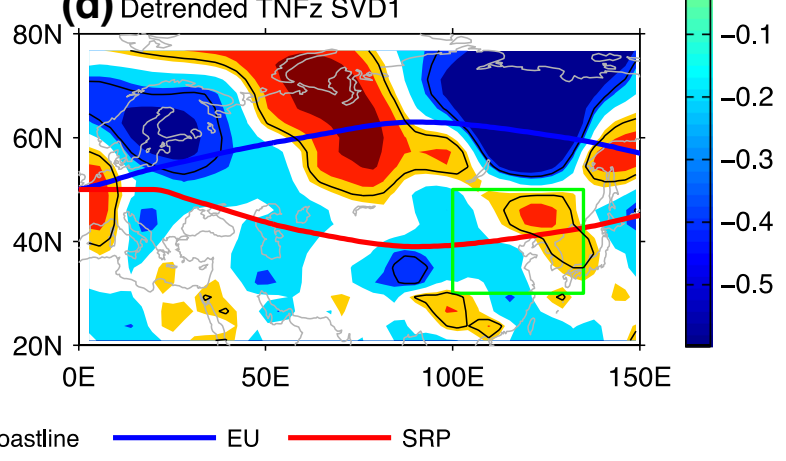

(f) Standard TNFZ PC1

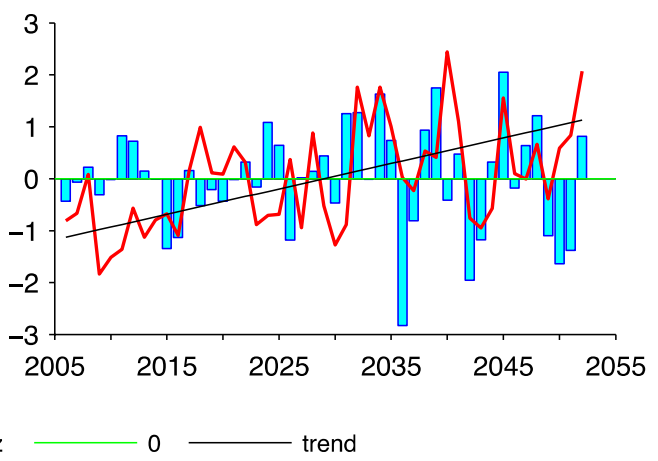

and normalized leading PC1 of vertical TNF (red line) and detrended vertical TNF (f) in July 2006-2055, with multi-model simulations of CMIP5 and RCP4.5-scenario

Arctic ice loss slows the progression of Rossby waves by weakening the zonal winds and increasing the wave amplitude, which is helpful to summer extreme events including Eurasian heat waves and droughts (Schubert et al. 2014). How does the forcing source of Eurasia relate to PDO/SST anomaly, Arctic ice loss and other decadal forcing? It need further investigated. Moreover, sensitivity simulation on our study should be further performed in the next research.

Acknowledgements This research was jointly supported by the National Key R\&D Program of China (Grant no. 2016YFA0600702), the National Natural Science Foundation of China under Grant nos. 
41630426, 41625019, and by Qing Lan Project and the Priority Academic Program Development of the Jiangsu Higher Education Institutions (PAPD). We would like to thank diurnal precipitation from the China Meteorological Administration website (http://cdc.cma.gov.cn/ home.do), ECMWF for providing the ERA-interim data (http://apps. ecmwf.int/datasets/), and SST dataset.

Open Access This article is distributed under the terms of the Creative Commons Attribution 4.0 International License (http://creativeco mmons.org/licenses/by/4.0/), which permits unrestricted use, distribution, and reproduction in any medium, provided you give appropriate credit to the original author(s) and the source, provide a link to the Creative Commons license, and indicate if changes were made.

\section{References}

Ambrizzi T, Hoskins BJ, Hsu HH (1995) Rossby wave propagation and teleconnection patterns in the austral winter. J Atmos Sci 52:3661-3672

Barnston AG, Livezey RE (1987) Classification, seasonality and persistence of low-frequency atmospheric circulation patterns. Mon Weather Rev 115(6):1083-1126

Burke EJ, Brown SJ (2008) Evaluating uncertainties in the projection of future drought. J Hydrometeorol 9(2):292-299

Byun HR, Wilhite DA (1999) Objective quantification of drought severity and duration. J Clim 12:2747-2756

Cheng H, Edwards RL, Haug GH (2010) Comment on "On linking climate to Chinese dynastic change: spatial and temporal variations of monsoonal rain". Chin Sci Bull 55(32), 3734-3737

Dai A, Trenberth KE, Qian TT (2004) A global dataset of Palmer drought severity index for 1870-2002: relationship with soil moisture and effects of surface warming. J Hydrometeor 5:1117-1130

Dee DP, Uppala S, Simmons A, Berrisford P, Poli P, Kobayashi S, Andrae U, Balmaseda M, Balsamo G, Bauer P, Bechtold P, Beljaars ACM, van de Berg L, Bidlot J, Bormann N, Delsol C, Dragani R, Fuentes M, Geer AJ, Haimberger L, Healy SB, Hersbach H, Hólm EV, Isaksen L, Kållberg P, Köhler M, Matricardi M, McNally AP, Monge-Sanz BM, Morcrette JJ, Park BK, Peubey C, De Rosnay P, Tavolato C, Thépaut J, Vitart F (2011) The ERAInterim re-analysis: configuration and performance of the data assimilation system. QJR Meteorol Soc 137:553-597

Ding Q, Wang B (2005) Circumglobal teleconnection in the NH summer. J Clim 18:3483-3503

Enomoto T (2004) Interannual variability of the Bonin high associated with the propagation of Rossby waves along the Asian jet. J Meteorol Soc Jpn 82:1019-1034

Enomoto T, Hoskins BJ, Matsuda Y (2003) The formation mechanism of the Bonin high in August. Q J R Meteorol Soc 129:157-178

Francis JA, Vavrus SJ (2012) Evidence linking Arctic amplification to extreme weather in mid-latitudes. Geophys Res Lett 39:L06801. https://doi.org/10.1029/2012GL051000

Gong DY, Ho CH (2003) Arctic oscillation signals in the East Asian summer monsoon. J Geophys Res 108:4066. https://doi. org/10.1029/2002JD002193

Goswami BN, Ajaya Mohan RS (2001) Intraseasonal oscillations and interannual variability of the Indian summer monsoon. J Clim 14(4):1180-1198

Hoskins B, Woollings T (2015) Persistent extratropical regimes and climate extremes. Curr Clim Change Rep 1(3):115-124

Hoskins BJ, James IN, White GH (1983) The shape, propagation and mean-flow interaction of large scale weather systems. J Atmos Sci 40:1595-1612
Huang RH, Chen JL, Huang G (2007) Characteristics and variations of the East Asian monsoon system and its impacts on climate disasters in China. Adv Atmos Sci 24:993-1023

Huang J, Ji M, Xie Y, Wang S, He Y, Ran J (2016a) Global semi-arid climate change over last 60 years. Clim Dyn 46:1131-1150

Huang J, Yu H, Guan X, Wang G, Guo R (2016b) Accelerated dryland expansion under climate change. Nat Clim Change 6(2):166-172

Kim DW, Byun HR, Choi KS, Oh SB (2011) A spatiotemporal analysis of historical droughts in Korea. J Appl Meteorol Climatol 50:1895-1912

Kosaka Y, Nakamura H (2006) Structure and dynamics of the summertime Pacific-Japan teleconnection pattern. Q J R Meteorol Soc 132(619):2009-2030

Lee SM, Byun HR, Tanaka HL (2012) Spatiotemporal characteristics of drought occurrences over Japan. J Appl Meteorol Climatol 51:1087-1098

Li J, Yu RC, Zhou TJ (2008) Teleconnection between NAO and climate downstream of the Tibetan Plateau. J Clim 21:4680-4690

Lu R, Oh JH, Kim BJ (2002) A teleconnection pattern in upper-level meridional wind over the North African and Eurasian continent in summer. Tellus 54A:44-55

$\mathrm{Ma} \mathrm{Z,} \mathrm{Fu} \mathrm{C} \mathrm{(2006)} \mathrm{Some} \mathrm{evidence} \mathrm{of} \mathrm{drying} \mathrm{trend} \mathrm{over} \mathrm{northern}$ China from 1951 to 2004. Chin Sci Bull 51:2913-2925

McKee TB, Doesken NJ, Kleist J (1993) The relationship of drought frequency and duration to time scales. In: Proceedings of 8th conference on applied climatology, Anaheim, CA. American Meteorological Society, pp 179-184

Menon S, Hansen J, Najarenko L, Luo Y (2002) Climate effects of black carbon aerosols in China and India. Science 297:2250-2252

Nitta T (1987) Convective activities in the tropical western Pacific and their impact on the NH summer circulation. J Meteorol Soc Jpn 65:373-390

Orlowsky B, Seneviratne SI (2012) Global changes in extreme events: regional and seasonal dimension. Clim Change 110:669-696

Palmer WC (1965) Meteorological drought. U.S. Department of Commerce, Weather Bureau, research paper 45

Petoukhov V, Petri S, Rahmstorf S, Coumou D, Kornhuber K, Schellnhuber HJ (2016) The role of quasi-resonant planetary wave dynamics in recent boreal spring-to-autumn extreme events. Proc Natl Acad Sci 113(25):6862-6867

Qian C, Zhou T (2014) Multidecadal variability of northern China aridity and its relationship to PDO during 1900-2010. J Clim 27:1210-1222

Qian C, Yu JY, Chen G (2014) Decadal summer drought frequency in China: the increasing influence of the Atlantic multi-decadal oscillation. Environ Res Lett 9(12):124004. https://doi. org/10.1088/1748-9326/9/12/124004

Sato N, Takahashi M (2006) Dynamical processes related to the appearance of quasi-stationary waves on the subtropical jet in the midsummer NH. J Clim 19:1531-1544

Scaife AA, Woollings T, Knight J, Martin G, Hinton T (2010) Atmospheric blocking and mean biases in climate models. J Clim 23:6143-6152

Schubert SD, Wang H, Koster RD, Suarez MJ, Groisman PY (2014) Northern Eurasian heat waves and droughts. J Clim 27(9):3169-3207

Selvey LA, Rutherford S, Dodds J, Dwyer S, Robinson SM (2014) The impact of climate-related extreme events on public health workforce and infrastructure-how can we be better prepared? Aust N Z J Publ Health 38:208-210

Sheffield J, Wood EF (2008) Projected changes in drought occurrence under future global warming from multi-model, multi-scenario, IPCC AR4 simulations. Clim Dyn 31(1):79-105

Sillman J, Kharin VV, Zhang X, Zwiers FW, Bronaugh D (2013a) Climate extremes indices in the CMIP5 multimodel ensemble: 
part 1. Model evaluation in the present climate. J Geophys Res Atmos 118:1-18

Sillman J, Kharin VV, Zwiers FW, Zhang X, Bronaugh D (2013b) Climate extremes indices in the CMIP5 multimodel ensemble: part 2. Future climate projections. J Geophys Res Atmos 118:2473-2493

Simmons AJ, Wallace JM, Branstator GW (1983) Barotropic wave propagation and instability, and atmospheric teleconnection patterns. J Atmos Sci 40:1363-1392

Song F, Zhou T (2014) Interannual variability of East Asian summer monsoon simulated by CMIP3 and CMIP5 AGCMs: skill dependence on Indian Ocean-western Pacific anticyclone teleconnection. J Clim 27:1679-1697

Sun C, Yang S (2012) Persistent severe drought in southern China during winter-spring 2011: large-scale circulation patterns and possible impacting factors. J Geophys Res 117:D10112. https:// doi.org/10.1029/2012JD017500

Takaya K, Nakamura H (2001) A formulation of a phase independent wave-activity flux for stationary and migratory quasi-geostrophic eddies on a zonally varying basic flow. J Atmos Sci 58:608-627

Tebaldi C, Hayhoe K, Arblaster J, Meehl G (2006) Going to extremes. An intercomparison of model-simulated historical and future changes in extreme events. Clim Change 79:185-211

Wallace JM, Gutzler DS (1981) Teleconnections in the geopotential height field during the Northern Hemisphere winter. Mon Weather Rev 109(2):784-812

Wang H (2001) The weakening of Asian monsoon circulation after the end of 1970's. Adv Atmos Sci 18:376-386

Wu B, Zhou T, Li T (2009) Seasonally evolving dominant interannual variability modes of East Asian climate. J Clim 22:2992-3005

Wu Z, Li J, Jiang Z, He J, Zhu X (2012) Possible effects of the NAO scillation on the strengthening relationship between the East Asian summer monsoon and ENSO. Int J Climatol 32:794-800

Yilmaz AG, Hossain I, Perera BJC (2014) Effect of climate change and variability on extreme rainfall intensity-frequency-duration relationships: a case study of Melbourne. Hydrol Earth Syst Sci 18:4065-4076

Yu RC, Wang B, Zhou T (2004) Tropospheric cooling and summer monsoon weakening trend over East Asia. Geophys Res Lett 31:L22212. https://doi.org/10.1029/2004GL021270

Zhang Q, Pan X (2009) Drought (in Chinese). China Meteorological Press, Beijing

Zhang L, Zhou T (2015) Drought over East Asia: a review. J Clim 28(8):150203142724009

Zhang X, Hegerl G, Zwiers F, Kenyon J (2005) Avoiding inhomogeneity in percentile-based indices of temperature extremes. J Clim 16:1641-1651

Zhang J, Li L, Li D, Deng W (2015) Summer droughts in the north portion of the Yellow river basin in association with recent Arctic ice loss. Int J Climatol 35:2849-2859

Zhang J, Tang Q, Chen HS (2017) Northward shift in circulation system over the Asian mid-latitudes linked to an increasing heating anomaly over the northern Tibetan Plateau during the past two decades. Int J Climatol 37(2):834-848

Zhang J, Liu C, Chen H (2018) The modulation of Tibetan Plateau heating on the multi-scale northernmost margin activity of East Asia summer monsoon in northern China. Glob Planet Change 161:149-161

Zhou TJ, Yu RC (2005) Atmospheric water vapor transport associated with typical anomalous summer rainfall patterns in China. $\mathrm{J}$ Geophys Res 110:D08104. https://doi.org/10.1029/2004JD005413

Zhou TJ, Yu R, Li H, Wang B (2008) Ocean forcing to changes in global monsoon precipitation over the recent half-century. J Clim 21:3833-3852

Zou X, Zhang Q (2008) Preliminary studies on variations in droughts over China during past 50 years (in Chinese). J Appl Meteorol Sci 19:679-687 